\title{
Exploiting Hexafluoroisopropanol (HFIP) in Lewis and Brønsted Acid-Catalyzed Reactions
}

Received 00th January 20xx, Accepted 00th January 20xx DOI: $10.1039 / x 0 x \times 00000 x$

\author{
Valentyn Pozhydaiev, ${ }^{\mathrm{a}}$ Martin Power, ${ }^{\mathrm{a}}$ Vincent Gandon, ${ }^{\mathrm{b}}$ Joseph Moran*a and David Lebœuf*a
}

Hexafluoroisopropanol (HFIP) is a solvent with unique properties that has recently gained attention for promoting a wide range of challenging chemical reactions. It was initially believed that HFIP was almost exclusively involved in the stabilization of cationic intermediates, owing to its high polarity and low nucleophilicity. However, in many cases, the mechanism of action of HFIP appears to be more complex. Recent findings reveal that many Lewis and Brønsted acid-catalyzed transformations conducted in HFIP additionally involve cooperation between catalyst and HFIP hydrogen-bond clusters, akin to Lewis- or Brønsted acid-assisted-Brønsted acid catalysis. This feature article showcases the remarkable versatility of HFIP in Lewis and Brønsted acid-catalyzed reactions, with an emphasis on examples yielding mechanistic insight.

\section{Introduction}

Over the last decade, the use of hexafluoroisopropanol (HFIP) as a solvent has grown owing to its remarkable combination of intrinsic properties, including its ability to stabilize cationic and radical species, to strongly donate hydrogen bonds, to exhibit low nucleophilicity and to remain inert under redox stress. ${ }^{1}$ The various facets of this solvent have been used to solve problems in all realms of homogeneous catalysis (transition-metal, Lewis acid and Brønsted acid catalysis), as well as in electrochemistry and photoredox processes. In many cases, it can be used as the sole promoter for reactions that otherwise require a catalyst, particularly for reactions involving hypervalent iodine reagents. This once rare solvent is now routinely evaluated during the development of new transformations. By taking advantage of HFIP's diverse properties, several groups have pushed the limits of transformations beyond what was thought to be possible in more traditional solvents, paving the way for its widespread use in the future.

Originally, the efficacy of HFIP was simply attributed to its ability to stabilize cationic intermediates. However, a flagship study on the epoxidation of alkenes by the group of Berkessel laid the foundation for a better comprehensive understanding of its properties. $^{2}$ They notably demonstrated that its $\mathrm{H}$-bond donating ability could be augmented through the formation of an $\mathrm{H}$-bond network between molecules of HFIP, a key feature that marked the re-emergence of this solvent in synthesis. Since then, a number of NMR and DFT studies devoted to elucidating the role of this solvent have suggested that its modes of activating substrates and catalysts are not as trivial as previously thought. Excellent reviews or accounts on the use of HFIP in synthesis have recently appeared. ${ }^{1}$ However, they did not focus on the mechanisms by which HFIP interacts with

a. Institut de Science et d'Ingénierie Supramoléculaires (ISIS), CNRS UMR 7006, Université de Strasbourg, 67000 Strasbourg, France.E-mail:moran@unistra.fr.Email: dleboeuf@unistra.fr

b. Institut de Chimie Moléculaire et des Matériaux d'Orsay (ICMMO), CNRS UMR 8182, Université Paris-Saclay, 91405 Orsay, France. substrates and with Lewis or Brønsted acid catalysts. This feature article will highlight these aspects, which have been an important part of our research interests over the past five years. It will mostly cover the period 2010-2020, during which time many studies started to shed light on the role played by HFIP in catalytic reactions.

\section{HFIP: Chemical and Physical Properties}

HFIP is a unique solvent in the sense that it possesses an atypical combination of properties not found in classic solvents. For instance:

(1) the presence of two trifluoromethyl groups imparts a strong negative inductive effect to HFIP, such that it is $>10^{7}$ times more acidic $\left(\mathrm{p} K_{a}=9.3\right)$ than $i \mathrm{PrOH}\left(\mathrm{p} K_{a}=17.1\right)$. HFIP has an acidity range (the acidities achievable in a given solvent) with the same order of magnitude as water. However, due to its reduced basicity, this range is shifted to a considerably more acidic regime comparable to formic acid. Its low nucleophilicity $\left(N_{O T S}=-4.23\right)^{3}$ reduces its ability to compete for electrophiles, limiting undesirable side reactions. In fact, Mayr's solvent nucleophilicity parameter for 99:1 HFIP/water is the lowest value when compared to any classic solvent $\left(N_{1}=-1.93\right){ }^{4}$

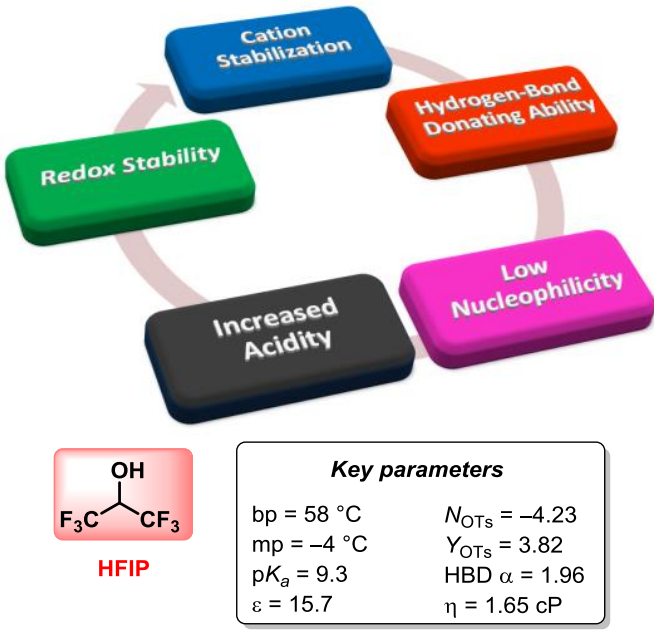

Scheme 1. Properties of hexafluoroisopropanol (HFIP). 
(2) HFIP has a strong hydrogen-bond donor ability (HBD $\alpha=1.96),{ }^{5}$ which is enhanced by the formation of an $\mathrm{H}$-bond network between multiple molecules of HFIP, notably its dimer and trimer. ${ }^{2}$ Additionally, $\mathrm{H}$-bond clusters between HFIP and various Lewis bases (THF, piperidine, tertiary amines, etc.) have been identified in the literature. ${ }^{6}$

(3) HFIP's high polarity $(\varepsilon=15.7)$ associated with its low nucleophilicity also make it a solvent of choice for generating and investigating cationic species. ${ }^{7}$ As emphasized by solvatochromic experiments of roughly 360 compounds, $\operatorname{HFIP}\left(E^{N_{T}}=1.068\right)$ is one of the few solvents (with the exception of a few liquid organic salts) to be off the chart defined by $E^{N_{T}}\left(\mathrm{Me}_{4} \mathrm{Si}\right)=0$ and $E^{\mathrm{N}_{\mathrm{T}}}\left(\mathrm{H}_{2} \mathrm{O}\right)=1 .{ }^{8}$ Furthermore, HFIP has strong ionizing power $\left(Y_{\text {OTS }}=3.82\right) .{ }^{3}$ There is ongoing discussion over whether HFIP stabilizes cations (thermodynamic phenomenon) or simply lets them persist long enough to react (kinetic phenomenon).

(4) While it is not relevant to this feature article, HFIP is redox stable, which makes it an ideal solvent for electrochemistry and photoredox processes as well as transformations requiring highly oxidizing conditions.

This unique combination of properties makes HFIP good at mediating addition or substitution reactions without the discrete generation of activated electrophilic intermediates and without the use of transition metals, both of which can sometimes be toxic and costly. In particular, it is adept at mediating $\mathrm{C}-\mathrm{C}$ and $\mathrm{C}$-heteroatom bond forming reactions from simple alcohols, alkenes and cyclopropanes, and is often the only effective solvent for substrates that are highly deactivated or prone to sequester the catalyst.

\section{Friedel-Crafts Alkylations}

Over the past decade, HFIP has often been shown to outperform traditional solvents (toluene, dichloromethane, nitromethane, etc.) in Lewis and Brønsted acid-catalyzed dehydrative nucleophilic substitutions of alcohols. This is especially true for the Friedel-Crafts reaction, one of the most prominent processes to functionalize (hetero)arenes. ${ }^{9}$

It is well-established that activated alcohols, including propargyl, allyl and benzyl alcohols, can easily ionize in the presence of Brønsted and Lewis acid catalysts to form a stabilized carbocation species that can be engaged in a subsequent transformation. However, deactivated alcohols, especially those bearing strong electron-withdrawing groups, are usually unable to engage in this type of reaction and, thus typically require pre-activation. ${ }^{10}$ One solution that has emerged in the literature is the combination of a Brønsted acid catalyst with HFIP as a solvent. For instance, we demonstrated that a promoter system consisting of TfOH and HFIP enabled Friedel-Crafts reactions of highly deactivated benzylic alcohols. ${ }^{11,12}$ A wide range of previously unreactive electronically deactivated alcohols efficiently reacted with various nucleophiles (Scheme 2). As deactivated alcohols are less prone to dehydrative ether formation, the protocol was even compatible with poor nucleophiles such as benzene or halobenzenes. We also succeeded to extend this reactivity to other challenging substrates such as alcohols bearing an adjacent trifluoromethyl group, affording synthetically valuable fluorinated building blocks. ${ }^{13}$ This approach is all the more relevant when we consider that, previously, $\alpha$-trifluoromethyl cations had only been generated by stepwise or in situ pre-activation of alcohols using stoichiometric activating agents or concentrated solutions of strong

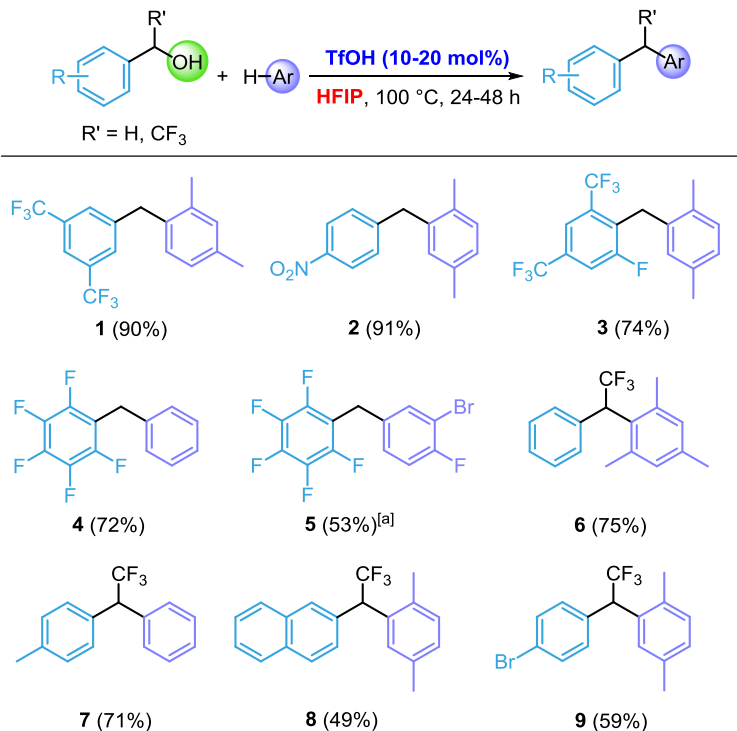

Scheme 2. Triflic acid-catalyzed Friedel-Crafts alkylation of highly deactivated benzyl alcohols in HFIP. [a] Mixture of regioisomers.

Brønsted acids. On the other hand, one drawback of this strategy is its incompatibility with anisole and heteroarene nucleophiles.

The beneficial role of HFIP in this reaction appears to come from its synergistic interaction with $\mathrm{TfOH}$, generating catalytically active $\mathrm{H}$-bond aggregates. NMR titration measurements were performed by adding TfOH to a solution of electrophile in HFIP (Figure 1). Upon increasing the concentration of TfOH, the NMR signal of the methine proton $\mathrm{H}_{z}$ of HFIP shifts downfield, while the methylene proton $\mathrm{H}_{m}$ of $\mathbf{1 0}$ does not shift significantly, indicating $\mathrm{TfOH}$ preferentially donates $\mathrm{H}$-bonds to HFIP rather than 10. In addition, kinetic experiments showed a fifth order concentration dependence with HFIP, which was consistent with the involvement of higher order HFIP aggregates in the reaction. When (-)-2,2,2-trifluoro-1-phenylethanol was subjected to the reaction conditions, the product was found to be present as a racemic mixture (Scheme 3 ). This outcome led to the conclusion that the reaction follows a $\mathrm{S}_{\mathrm{N}} 1$ pathway.

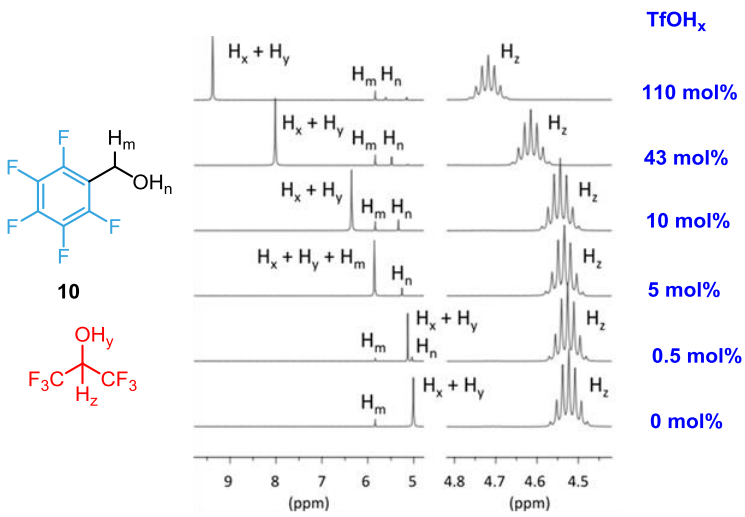

Figure 1. ${ }^{1} \mathrm{H}$ NMR titration of a mixture of HFIP (1 equiv) and 10 ( 0.050 equiv) with triflic acid. 


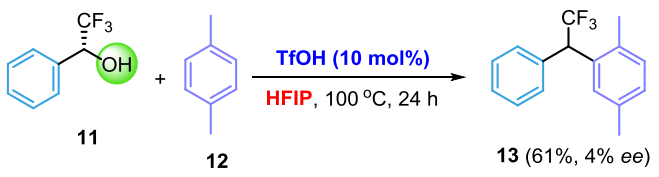

Scheme 3. Friedel-Crafts alkylation of enantioenriched $\alpha$ trifluoromethyl benzyl alcohol $\mathbf{1 1}$.

As an extension of this work, we reported subsequent studies on the synthesis of trifluoromethylated compounds from propargylic alcohols bearing trifluoromethyl groups by using either a Lewis or a Brønsted acid ( $\mathrm{FeCl}_{3}$ and $\mathrm{TfOH}$, respectively) as a catalyst in HFIP (Scheme 4). Depending on the substitution pattern of the substrate and the reaction conditions, $\mathrm{CF}_{3}$-substituted allenes, chromenes, alkenes or indenes could be selectively produced. ${ }^{14}$ Mechanistic studies to elucidate the role of $\mathrm{FeCl}_{3}$ revealed that the catalyst might be involved in the formation of a hidden Brønsted acid catalyst. ${ }^{15}$ As $\mathrm{HCl}$ could be produced by in situ hydrolysis of $\mathrm{FeCl}_{3}$, we envisioned that it could be the active catalyst; however, this possibility was excluded as only traces of products were obtained in the presence of $\mathrm{HCl}$. Based on previous findings, we suggested that ferric ions could enhance Brønsted acidity of HFIP by forming higher order aggregates, which would act as the active catalytic species.

Another alternative to achieve the Friedel-Crafts reaction is the use of boronic acid catalysts (BAC) as Lewis acids. ${ }^{16}$ The Hall group described the reactivity of moderately deactivated benzyl alcohols in a HFIP/nitromethane solvent mixture. In contrast to the system described above, highly deactivated substrates incorporating strong electron-withdrawing groups were mostly unreactive (Scheme 5). ${ }^{17}$

However, following their study on the Beckmann rearrangement, ${ }^{18}$ Hall and co-workers recently succeeded to improve and expand the reactivity with the development of a second-generation promoter system featuring the combination of a boronic acid and perfluoropinacol (Scheme 6), the latter being critical for the reactivity. ${ }^{19}$ In addition, they conducted in-depth mechanistic investigations to determine the active species.

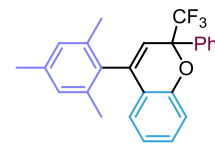

18 (quant.)
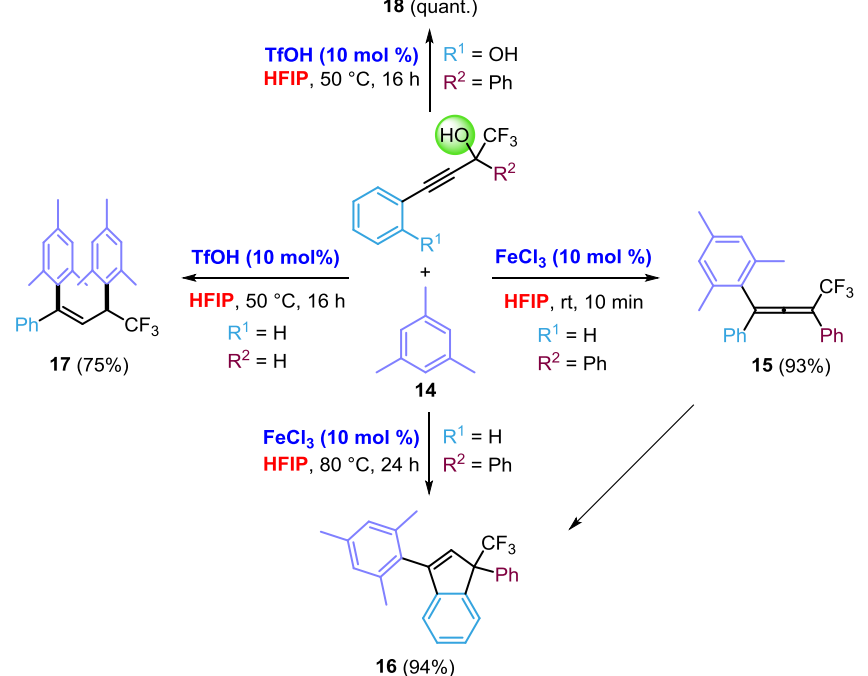

Scheme 4. Reactivity of $\alpha$-trifluoromethyl propargyl alcohols.

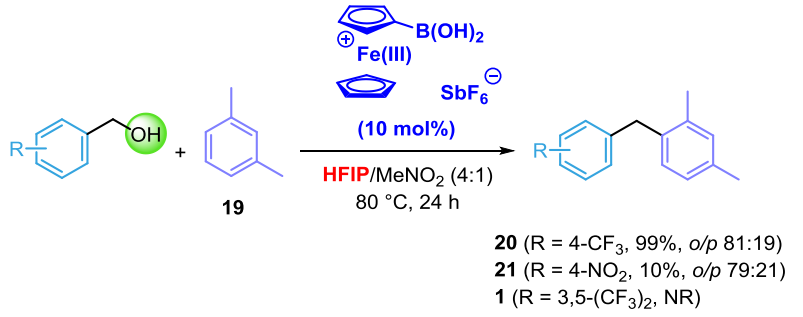

Scheme 5. Boronic acid-catalyzed Friedel-Crafts alkylation of benzyl alcohols.

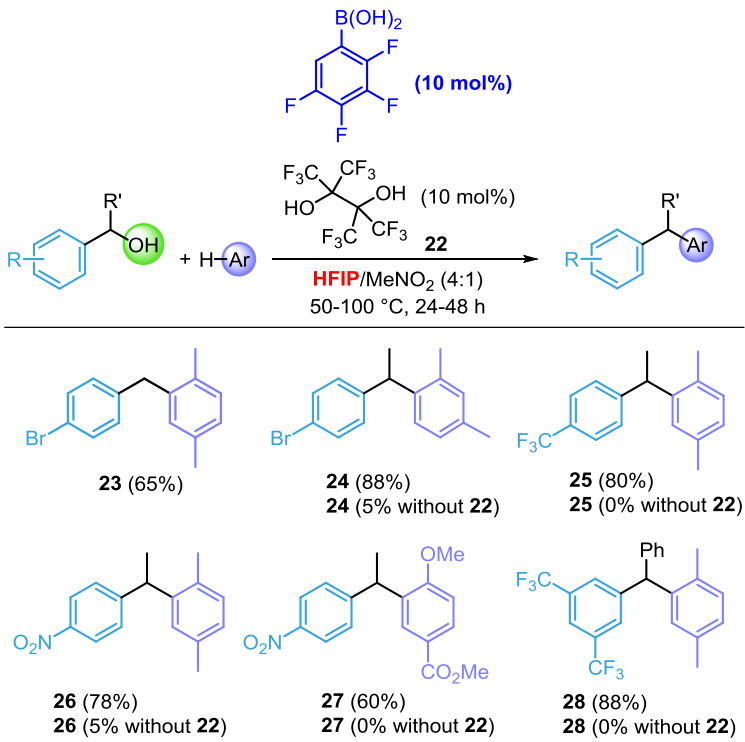

Scheme 6. Friedel-Crafts alkylation of benzyl alcohols promoted by a combination boronic acid/perfluoropinacol.

The authors hypothesized that perfluoropinacol could react with boron to form a boronic ester, thereby becoming sufficiently Lewis acidic to activate either HFIP or adventitious water. ${ }^{13} \mathrm{~B}$ NMR and ESIMS experiments detected tetra-coordinated species, supporting their hypothesis (Scheme 7). Moreover, the addition of a sterically demanding base 2,6-di-tert-butylpyridine turned out to be detrimental to the catalytic activity of this system. This result suggests that the protonation step is critical for successful catalytic turnover. From there, they envisioned several modes of activation for the benzylic alcohols: (1) a Lewis acid mode in which the alcohol is directly activated via coordination to the strongly Lewis acidic boronic ester, (2) a Brønsted acid mode that involves an acidic proton on HFIP, whose acidity is greatly enhanced by coordination to a Lewis acid. This proton is then captured by residual water, which delivers it to the alcohol, and (3) a Lewis acid-assisted Brønsted acid catalysis, ${ }^{20}$ which is similar to the previous mode, except that HFIP directly protonates the substrate. The role of hydronium ion was probed by control experiments, which were conducted in rigorously dried glassware with dry HFIP and $3 \AA \AA$ molecular sieves to exclude moisture. Those reaction conditions did not enable the formation of the corresponding product. The authors caution that this does not rule out the other activation modes and points to the need for further mechanistic investigations.

Those explanations echoed our own experimental observations. As it is widely accepted that boronic acids display a dual activation mode, it has been long assumed that the substrate was activated via coordination to boron, rendering the former more electrophilic. ${ }^{16 c}$ However, several notable cases in which HFIP was employed as a 

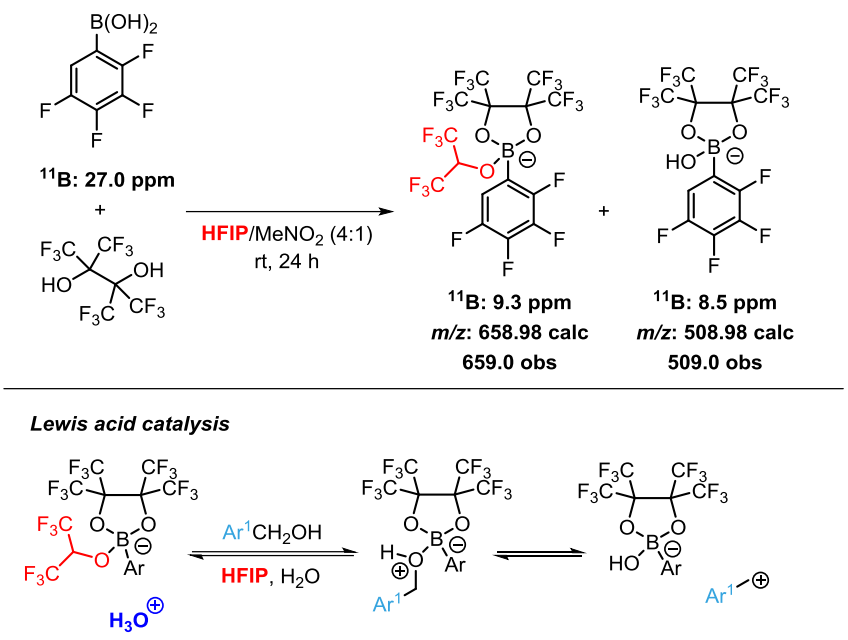

Brønsted acid catalysis

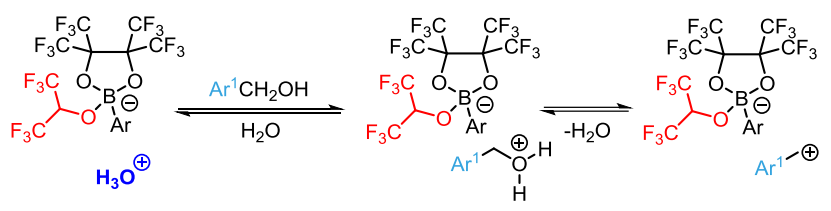

Lewis acid-assisted Brønsted acid catalysis
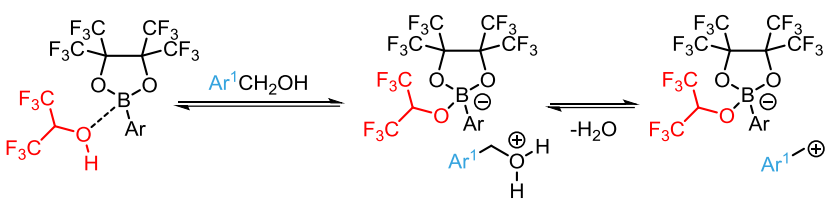

Scheme 7. Mechanistic proposal for the activation of the benzyl alcohols.

solvent prompted our group to question a mechanistic scenario involving covalent activation. Indeed, we noticed that boronic acids were able to trigger a cyclopropane ring opening in HFIP, although no hydroxyl group was present (Scheme 8) (see part 5 for details). ${ }^{21}$ Therefore, we reinvestigated a series of BAC reactions with alcohols and oximes. At the outset, we examined several boronic and Brønsted acids using the Gutmann-Beckett method, ${ }^{22}$ which revealed that strong Brønsted acids are very likely to be produced by B1 and B3 in HFIP (Figure 2). We also showed that similarly strong Brønsted acids could replace boronic acids to promote the same reactions (Scheme 8). Moreover, the reactivity of BAC was completely shut down when a hindered base 2,6-di-tertbutylpyridine was added. Another interesting feature is that, depending on the solvent used (toluene vs $\mathrm{HFIP} / \mathrm{MeNO}_{2}$ ), the relative and absolute acidity of the boronic acid catalyst systems can be completely reshuffled. For instance, B2 is more acidic than B1 in toluene but this is reversed in $\mathrm{HFIP} / \mathrm{MeNO}_{2}$. Furthermore, in $\mathrm{HFIP} / \mathrm{MeNO}_{2}$, B1 and B3 exhibit acidity between that of TFA and $\mathrm{TfOH}$. Based on these results, we believe that BAC transformations involve substrate activation by Brønsted acids, rather than typical covalent or Lewis acid mechanisms. The interaction between HFIP and boronic acid, presumably through covalent assembly, creates a strong Brønsted acid which is likely the true catalytically active species in those reactions.

Another remarkable example in which HFIP favors one reaction pathway over another was reported by Chan and co-workers regarding the chemoselective borane-catalyzed alkylation of unprotected arylamines (Scheme 9). ${ }^{23} \mathrm{~N}$-alkylated products were

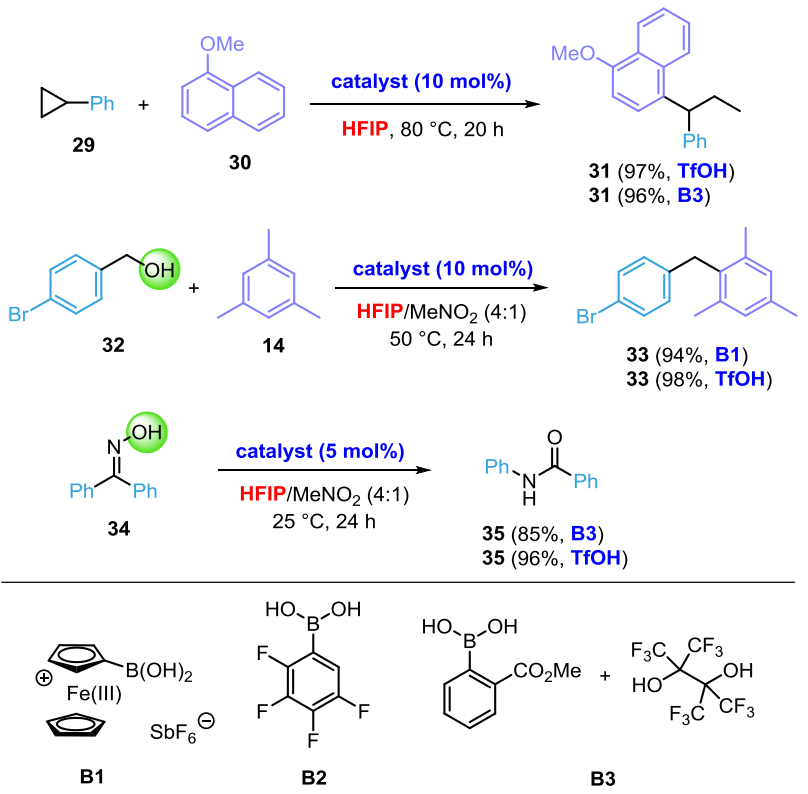

Scheme 8. Comparison of boronic acids and Brønsted acids as catalysts in the presence of HFIP.

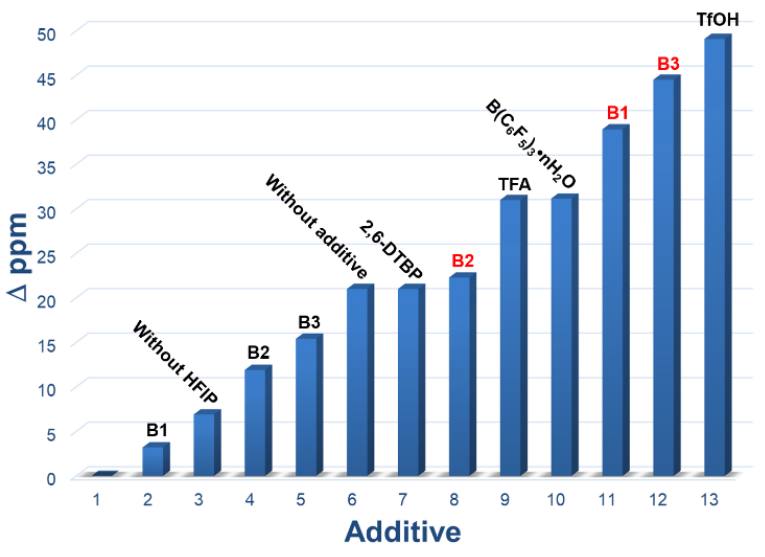

Figure 2. Gutmann-Beckett plot showing the influence of an additive (3 equiv.) on triethylphosphine oxide (TEPO) (1 equiv.) in $\mathrm{HFIP} / \mathrm{MeNO}_{2}$ (4:1) as expressed by the variations in chemical shift of the highest frequency signal observed in the ${ }^{31} \mathrm{P} N M R$ spectrum when compared to the reference TEPO in toluene- $d_{8}$. The values for $\mathbf{B 1}, \mathbf{B 2}$ and $\mathbf{B} 3$ (in black) are the references in toluene- $\mathrm{d}_{8}$ alone.

obtained in nitromethane, whereas C-alkylated products were exclusively formed when the reaction was performed in HFIP. Computational studies implied that the hydrogen bonding between the aniline and HFIP might render it less nucleophilic, favoring the Calkylation pathway. However, the interaction of nitromethane with the arylamine turns the latter into the hydrogen bonding donor, which makes the amine group electron-rich and more susceptible to undergo $\mathrm{N}$-alkylation. It is noteworthy that the ortho-C alkylation in HFIP is highly dependent on the benzyl alcohol used. Indeed, in the case of 1-phenylethan-1-ol derivatives, the reaction only proceeded with electron-rich substituents, while a substrate such as 1-(4fluorophenyl)ethan-1-ol did not provide the target product.

The group of Paquin also reported that benzyl fluorides could engage in Friedel-Crafts reactions in HFIP under mild reaction conditions without any additional catalyst. ${ }^{24}$ However, they demonstrated that the reactivity could be greatly improved by employing trifluoroacetic 


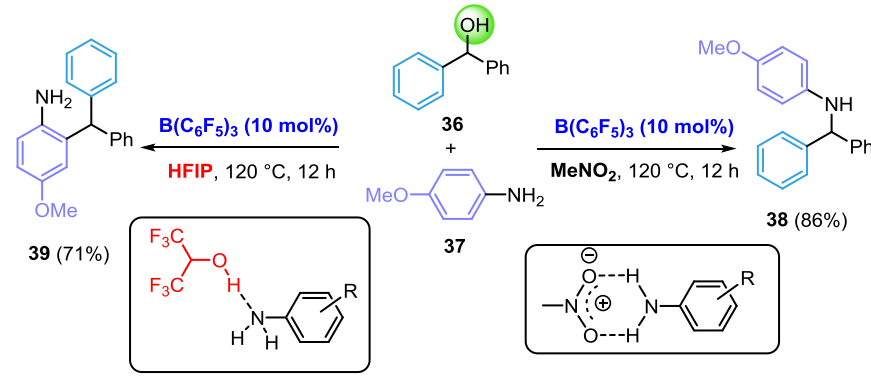

Scheme 9. $\mathrm{N}$-alkylation vs $\mathrm{C}$-alkylation for the reactivity of benzyl alcohols with anilines.

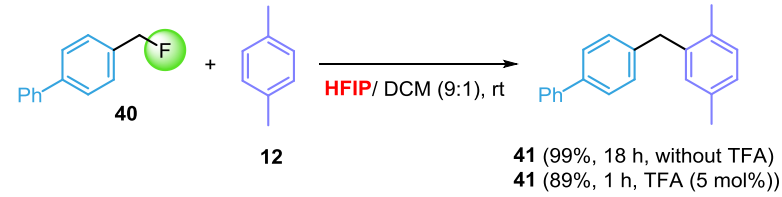

Scheme 10. Friedel-Crafts alkylation of benzyl fluoride $\mathbf{4 0 .}$

acid as catalyst, shortening the reaction time to $1 \mathrm{~h}$ (Scheme 10)..$^{25}$ Through NMR studies, they observed major modifications of the induction period with TFA (10 $\mathrm{min}$ instead of $170 \mathrm{~min})$, demonstrating again that the use of a Brønsted acid can significantly augment the acidity of the $\mathrm{H}$-bond network of HFIP molecules. Once the reaction initiates, the stronger acid $\mathrm{HF}$ is generated and becomes the kinetically most relevant catalyst.

There are other reactions in which HFIP is not directly involved as a Brønsted acid, but rather assists the process by facilitating a bond cleavage or stabilizing cationic reactive intermediates. ${ }^{26}$ For example, the cascade intramolecular Friedel-Crafts cyclization of fluorinated arylalkanes catalyzed by $\mathrm{B}\left(\mathrm{C}_{6} \mathrm{~F}_{5}\right)_{3}$ affords a large variety of spirobiindanes (Scheme 11). In that case, not only does HFIP stabilize numerous carbocations formed during the catalytic cycle, but it also decreases the Brønsted basicity of $\left[\mathrm{FB}\left(\mathrm{C}_{6} \mathrm{~F}_{5}\right)_{3}\right]^{-}$, preventing the elimination to a fluoroalkene that otherwise occurs when the reaction is conducted in 1,4-difluorobenzene. Additionally, the cyclization of a monofluorinated substrate was reported without even requiring a catalyst in the case of a benzyl fluoride substrate. HFIP is thought to facilitate $\mathrm{C}-\mathrm{F}$ bond cleavage in a similar manner as the previously mentioned reaction. In all those reactions, the fact that stoichiometric amounts of the strong acid HF are generated might also favor the activation of the $\mathrm{Csp}^{3}-\mathrm{F}$ and the subsequent formation of the carbocation intermediate. ${ }^{27}$

\section{Cyclizations}

Another field of research that was drastically impacted by the use of HFIP was that of cyclization, notably the aza-Piancatelli cyclization. ${ }^{28}$ This reaction consists of the transformation of 2-furylcarbinols into 4-aminocyclopentenones when anilines are employed as nucleophiles. Its interest lies in its potential to directly access frameworks such as aminocyclopentitols. The key intermediate for this transformation is the oxonium ion $\mathbf{5 5}$, which undergoes nucleophilic addition with the aniline, followed by a $4 \pi$-conrotatory electrocyclization. In our initial investigations, we designed an efficient catalytic system featuring $\mathrm{Ca}\left(\mathrm{NTf}_{2}\right)_{2} / n \mathrm{Bu}_{4} \mathrm{NPF}_{6}{ }^{29}$ in nitromethane to promote this transformation. ${ }^{30}$ However, during our study, we realized that numerous substrates could lead to side reactions at the carbinol position, including Friedel-Crafts and deoxyamination reactions, or could degrade at high temperatures
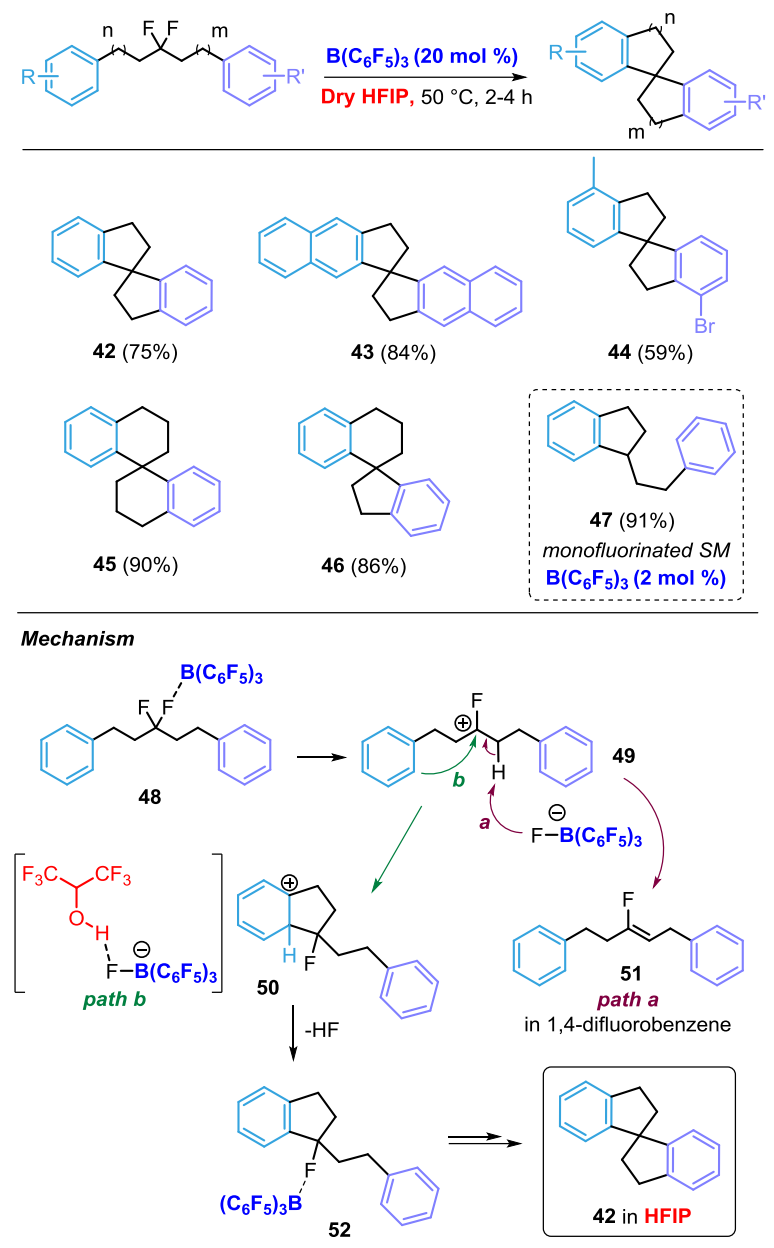

Scheme 11. Friedel-Crafts alkylation of fluorinated arylalkanes.

(Scheme 12). In particular, it affected 2-furylcarbinols incorporating alkene and cyclopropyl moieties or sterically hindered 2furylcarbinols and secondary anilines. ${ }^{31}$ Additionally, we noticed that anilines substituted by electron-donating groups were less reactive as they could trap the catalyst to form an "off-cycle" species.

Here, we hypothesized that the use of HFIP would promote the dissociation of this "off-cycle" species, thereby improving the reactivity of electron-rich anilines such as $p$-anisidine. While the reaction had to be carried out at $100{ }^{\circ} \mathrm{C}$ in nitromethane to obtain 61 , the same reaction could be conducted at room temperature with $90 \%$ efficiency in less than $2 \mathrm{~h}$ in HFIP (Scheme 13). ${ }^{31}$ By using these optimized reaction conditions, we were able to overcome many of
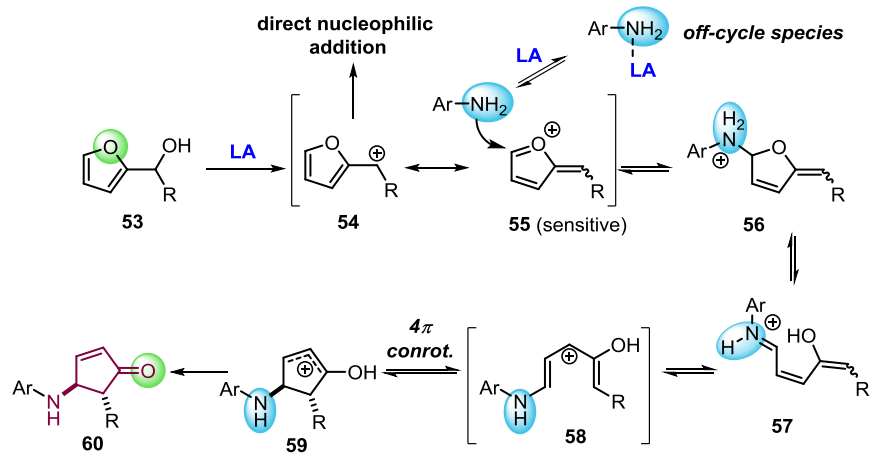

Scheme 12. Mechanism of the aza-Piancatelli cyclization. 


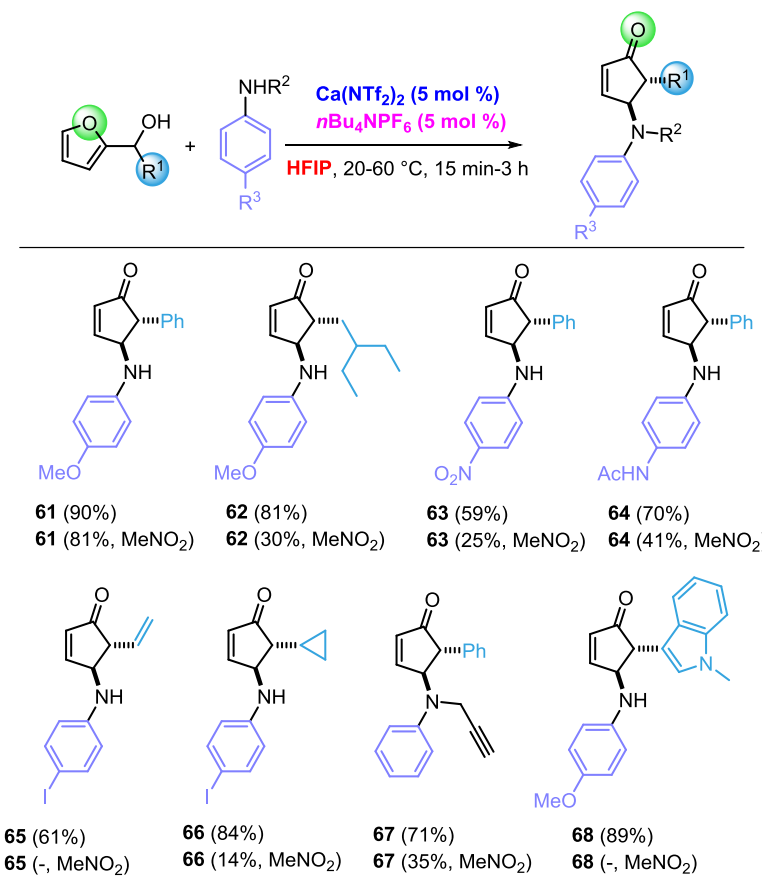

Scheme 13. Influence of the solvent on the aza-Piancatelli cyclization.

the problems associated with the aza-Piancatelli reaction to gain access to previously inaccessible compounds. In the case of electronrich substituents such as indoles, the intrinsic acidity of HFIP was even sufficient to initiate the reaction in the absence of a Lewis acid delivering the target product in high yields.

The impact of HFIP on the outcome of the reaction prompted us to study the acidity of the system using Childs' method (Scheme 14), ${ }^{32}$ which clearly pointed towards a cooperation between HFIP and calcium. Lastly, DFT modelling suggested the involvement of $\mathrm{H}$-bond aggregates between molecules of HFIP, whose acidity was accentuated by their coordination to the calcium Lewis acid (Scheme 3 ). This effect results in (1) an increase of the partial positive charge at the $\alpha$-carbon of the furan moiety, and (2) a weakening of the C-O bond, thereby facilitating the aza-Piancatelli pathway under milder reaction conditions. In that case, a mode of activation of the 2furylcarbinol with calcium was also considered. However, the results obtained were not consistent with this proposal.

The potential of this system was further exploited in one-pot reaction sequences featuring the aza-Piancatelli cyclization as a key step to prepare densely functionalized cyclopenta[b]pyrroles and cyclopenta[b]pyrrolines (hydroamination), 33 cyclopenta[b]piperazinones (annulation with aza-oxyallyl cation) ${ }^{34}$ and tetrahydrobenzo[b]azepines (Michael addition). ${ }^{35}$ The most

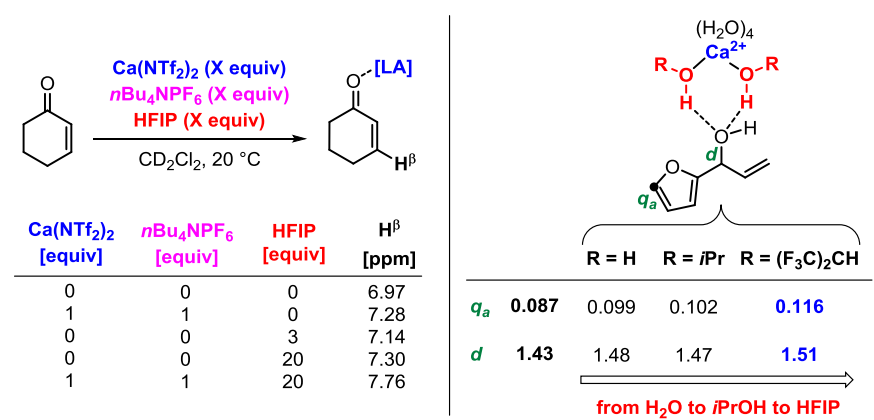

Scheme 14. Role of HFIP in the aza-Piancatelli cyclization.

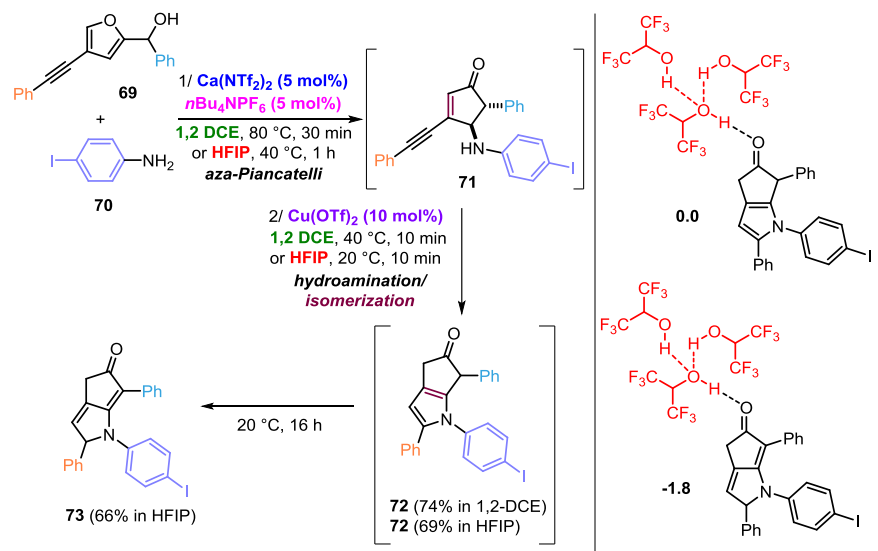

Scheme 15. Dearomatization of cyclopenta[b]pyrroles in HFIP. $\Delta \mathrm{G}_{298}$ in $\mathrm{kcal} / \mathrm{mol}$.

relevant case is the first one. ${ }^{33 b}$ When the reaction was conducted in 1,2-DCE, cyclopenta[b]pyrrole $\mathbf{7 2}$ was obtained following a hydroamination/isomerization process (Scheme 15). The use of HFIP as solvent initially afforded the same compound. However, a prolonged reaction time led to the complete dearomatization of the product to give cyclopenta[b]pyrroline $\mathbf{7 3}$ via the activation of the carbonyl moiety, as corroborated by DFT computations.

Donohoe and co-workers have recently shown that using HFIP as solvent was also crucial in a one-pot Ti(OiPr) ${ }_{4}$-catalyzed synthesis of polysubstituted tetrahydrofurans starting from a variety of activated alcohols and homoallylic alcohols (Scheme 16). ${ }^{36}$ Using this approach, they succeeded to control up to 4 contiguous stereocenters. They also demonstrated that other oxygen-containing
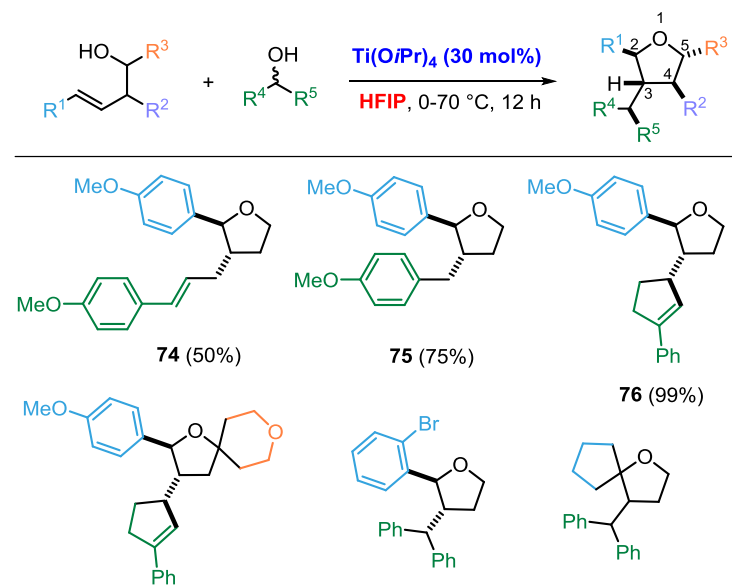

$76(99 \%)$

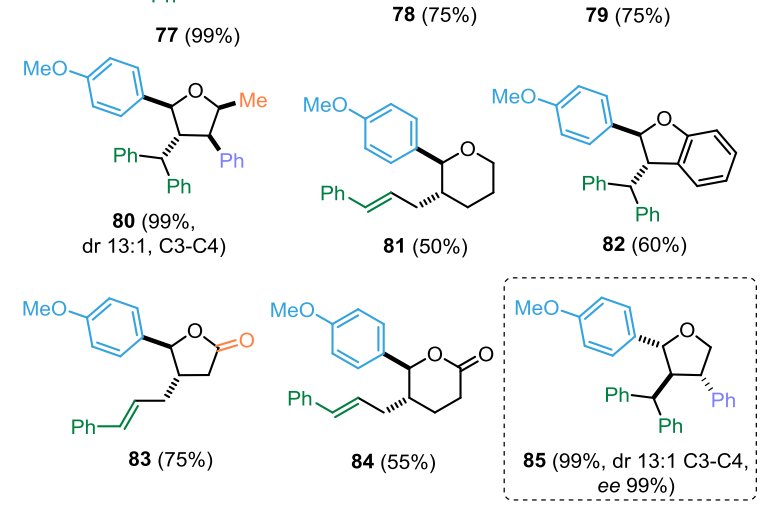

Scheme 16. Titanium(IV)-catalyzed synthesis of tetrahydrofurans and related compounds in HFIP. 


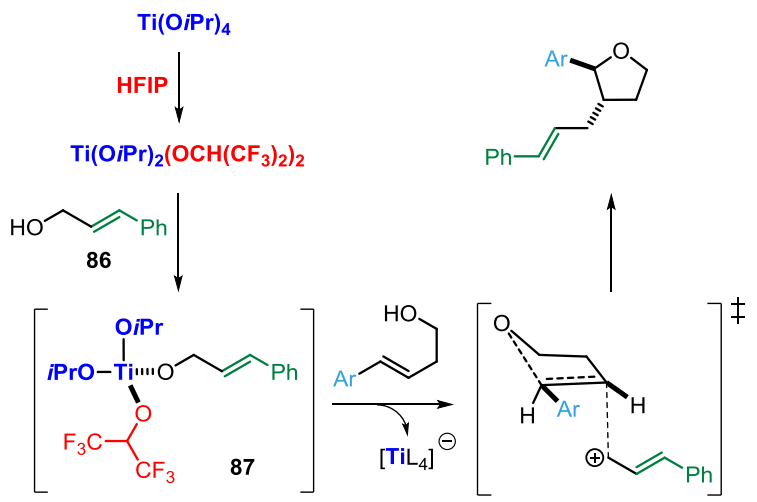

Scheme 17. Mechanistic proposal for the formation of tetrahydrofurans.

heterocycles such as tetrahydropyrans, benzofurans and lactone moieties could be prepared following this process. Moreover, the utilization of an enantiomerically pure homoallylic alcohol led to the corresponding tetrahydrofuran with complete transfer of chiral information. It is important to stress that this transformation could only be achieved in HFIP.

Regarding the determination of the true catalytic active species, the authors detected the formation of $\mathrm{Ti}(\mathrm{OiPr})_{2}\left(\mathrm{OCH}\left(\mathrm{CF}_{3}\right)_{2}\right)_{2}$ by NMR, resulting from a double ligand exchange (Scheme 17). This complex was then prepared separately and characterized before being engaged in a superstoichiometric reaction with cinnamyl alcohol (ratio 2:1), leading to a new species in which cinnamyl alcohol replaced one hexafluoroisopropoxy group. Lastly, adding the homoallylic alcohol to the reaction mixture afforded the targeted product, as the cyclization proceeds via concerted anti addition across the alkene. Considering the complexity of the reaction, it is likely that the ability of HFIP to stabilize the various cationic intermediates plays an important role.

\section{Hydroarylation Reactions}

As mentioned in part 3, several examples of Friedel-Crafts alkylation of highly deactivated alcohols have been described in the literature. However, there were no examples regarding the hydroarylation ${ }^{37}$ of highly deactivated styrenes, which represented a severe limitation.

The results obtained with the aza-Piancatelli cyclization emphasized that the acidity of HFIP could be increased to a large extent in the presence of a Lewis acid. Thus, we hypothesized that even unreactive electron-poor styrenes could be protonated to afford hydroarylated products after a subsequent trapping by an arene nucleophile (Scheme 18). ${ }^{38,39}$ In contrast with the abovementioned Friedel-Crafts examples, our protocol featuring the combination $\mathrm{Ca}(\mathrm{II}) / \mathrm{HFIP}$ demonstrated a wider substrate scope, notably being compatible with anisole, phenol and heteroarene derivatives. In addition, as previously observed, even poor nucleophiles such as benzene or bromobenzene could be employed because of the absence of oligomerization of the alkene.

As mentioned above with the aza-Piancatelli cyclization, computational studies implied that similar $\mathrm{Ca}(\mathrm{II})$-HFIP aggregates could operate (Scheme 19). A first set of calculations suggested that substrate activation by the calcium alone was very unlikely. The introduction of three HFIP molecules into the calcium coordination

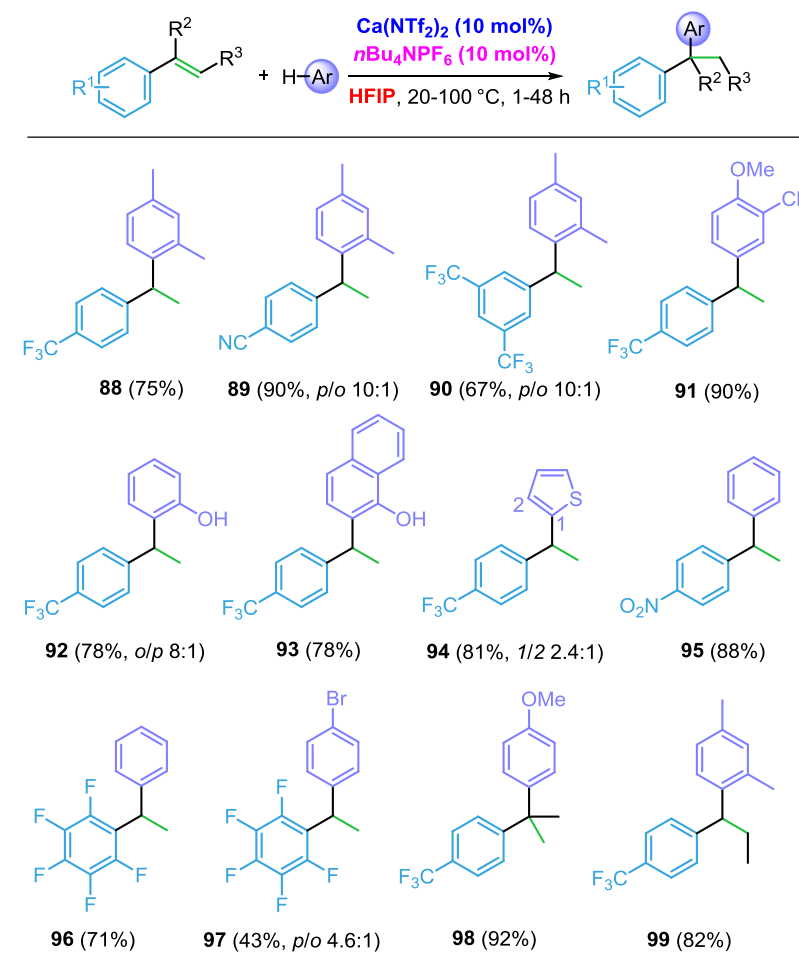

Scheme 18. Calcium(II)-catalyzed hydroarylation of highly deactivated styrenes in HFIP.

sphere enhanced the acidity of the former and enabled the endergonic protonation, which is immediately followed by toluene addition. The resulting Wheland-type intermediate should then rotate so that the $\mathrm{NTf}_{2}$ is spatially close enough to capture the proton. Since the addition of the arene creates a new stereogenic

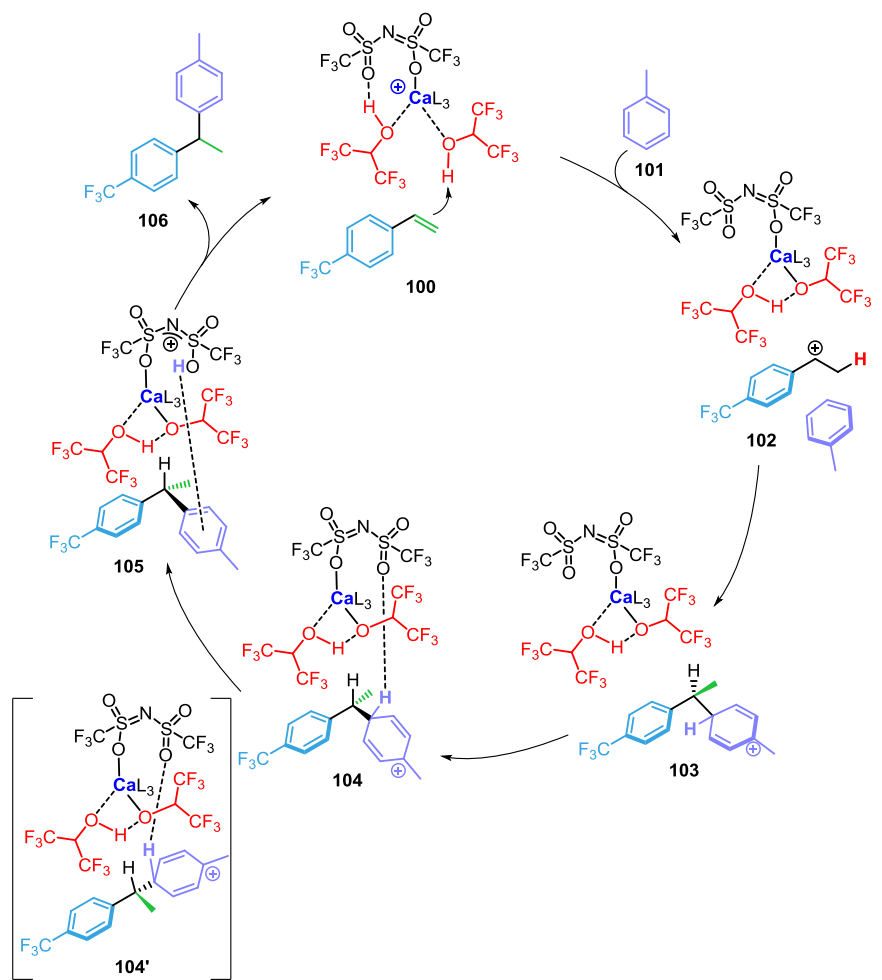

Scheme 19. Mechanistic proposal for the hydroarylation of 4trifluoromethylstyrene. 
center, and the calcium complex is chiral, both directions of rotation do not have the same energetic requirements. One of the diastereoisomers is however significantly more stable than the other one $\left(\Delta \mathrm{G}(\mathbf{1 0 4})=16.5 \mathrm{kcal} / \mathrm{mol}<\Delta \mathrm{G}\left(104^{\prime}\right)=23.9 \mathrm{kcal} / \mathrm{mol}\right)$. The subsequent deprotonation of the toluene moiety and the likely internal proton transfer from the $\mathrm{NTf}_{2}$ ligand to the HFIP alkoxide afford the final product and regenerate the active species.

Changing focus, the electrophilic activation of alkynes is an area of paramount importance in synthetic organic chemistry but remains mostly limited to transition metal catalysis. In principle, Lewis and Brønsted acid-catalyzed activation of alkynes in HFIP provides an intriguing metal-free alternative for this process. Magre and Rueping reported that the use of HFIP was also crucial for a highly selective ortho-alkenylation of anilines in the presence of $\mathrm{Mg}\left(\mathrm{NTf}_{2}\right)_{2}(\mathrm{Scheme}$ 20). ${ }^{40}$ Interestingly, the reactivity was maintained when a proton scavenger, 2,6-tert-butylpyridine, was added, in contrast to the outcome when this compound is added to many other Lewis acid promoted transformations in HFIP. However, the presence of HFIP was necessary, since $\mathrm{Mg}\left(\mathrm{NTf}_{2}\right)_{2}$ did not promote the transformation

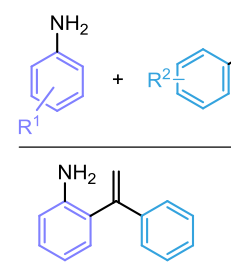

$107(74 \%)$

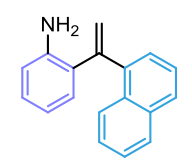

$110(72 \%)$

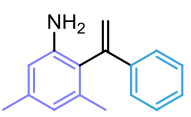

$113(74 \%)$

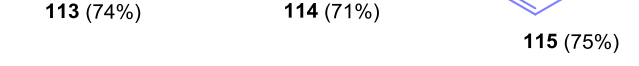

Mechanism

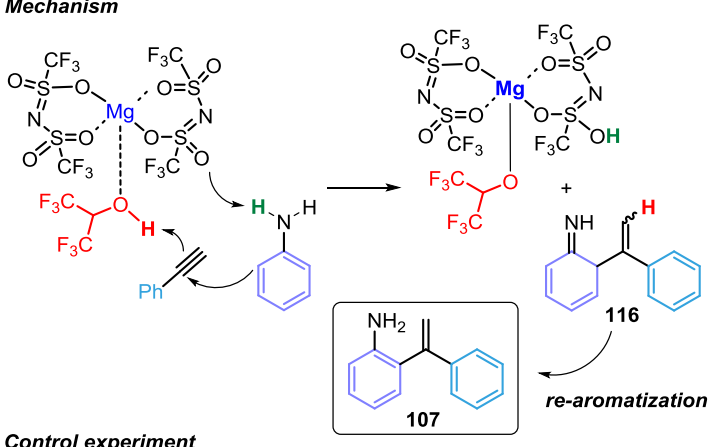

Control experiment

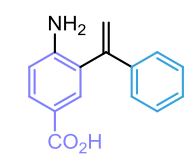

$111(72 \%)$

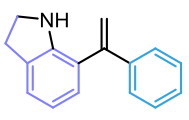

$114(71 \%)$

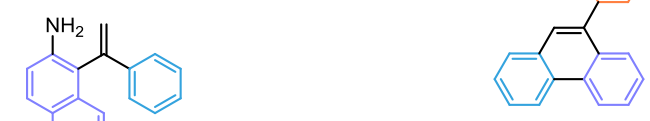

$119(77 \%)$

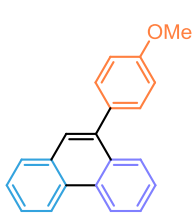

$122(96 \%)$

Mechanism
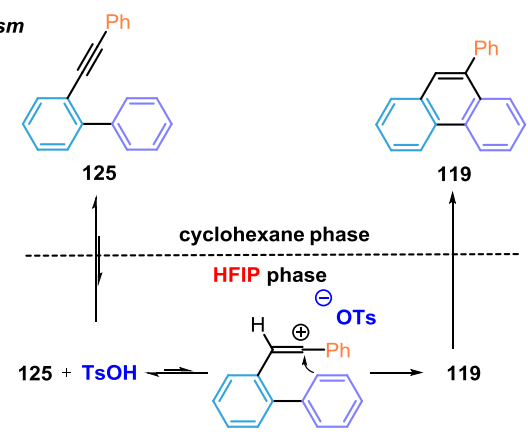

126

Scheme 21. Intramolecular hydroarylation of alkynes in the biphasic HFIP-cyclohexane system.

Scheme 20. Magnesium(II)-catalyzed hydroarylation of alkynes with aniline derivatives in HFIP. 
Ring-opening hydroarylation of cyclopropanes represents an excellent synthetic springboard to provide direct access to densely functionalized arylalkanes. While it is a well-established process regarding donor-acceptor cyclopropanes, ${ }^{43}$ by using TfOH in HFIP, we succeeded to push the boundaries of this transformation to include much less activated substrates, namely monosubstituted cyclopropanes bearing only a single stabilizing (carbonyl or aryl) substituent (Scheme 22).44,45 For most substrates, the reaction did not work in other solvents. In the case of some heteroarene nucleophiles, the reaction had to be conducted in the presence of the milder Brønsted acid catalyst $B\left(C_{6} F_{5}\right)_{3} \cdot \mathrm{H}_{2} \mathrm{O}$ to avoid its degradation by $\mathrm{TfOH}^{4}{ }^{44 a}$ The reaction was not limited to arene nucleophiles, but could also be extended to 1,3-dicarbonyls, azides and alcohols. ${ }^{44 a}$

On the basis of control experiments, in situ ${ }^{1} \mathrm{H}$ NMR titrations and DFT calculations, the nature of the reaction mechanism was found to be substrate-dependent. ${ }^{44 \mathrm{~b}}$ In the case of cyclopropyl ketone substrates, as for donor-acceptor cyclopropanes, the reaction appears to proceed through a homo-conjugate addition mechanism (Scheme 23), in which the ketone is protonated prior to ring-opening attack by the nucleophile to give the corresponding arenium 145 . Following a dearomatization and an enol/keto tautomerization, the targeted product is formed, releasing the catalytically active species and enabling the reaction turnover. Interestingly, titration experiments showed that reactive arene nucleophiles, such as 1,3,5-

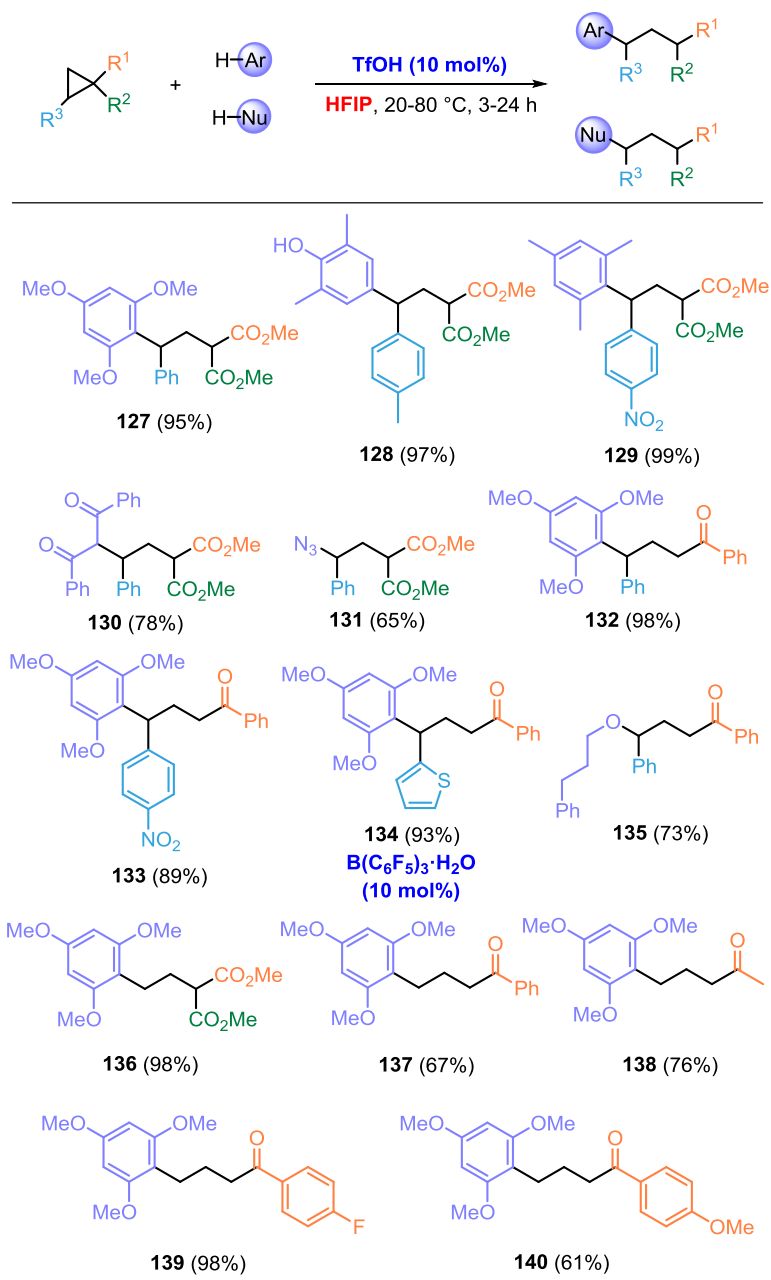

Scheme 22. Triflic acid-catalyzed hydroarylation of cyclopropane derivatives in HFIP.

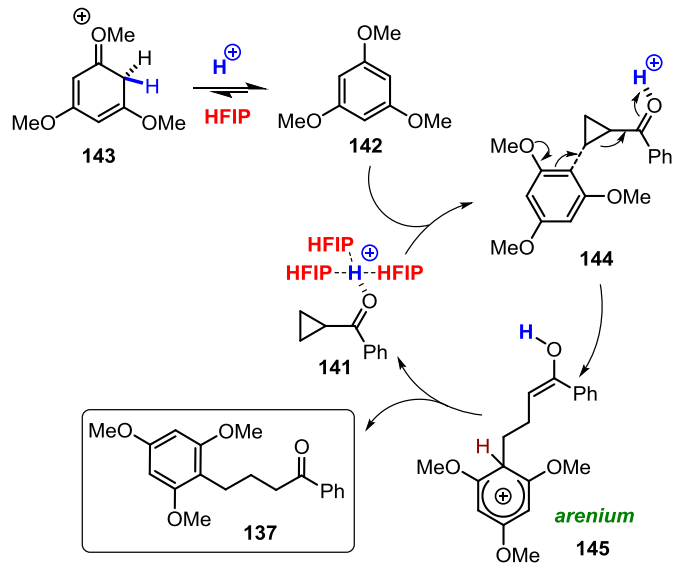

Scheme 23. Mechanistic proposal for the hydroarylation of cyclopropyl ketone 141

trimethoxybenzene, quantitatively outcompete the cyclopropyl ketone substrates for protonation by $\mathrm{TfOH}$. These protonated arenes were not observed in solvents other than HFIP. It thus remains unclear whether these protonated arenes are resting states for a proton catalyst, which is released in small amounts in equilibrium, or whether they directly act as catalysts themselves.

Computational studies by the groups of Zhang and Feng reinforced those hypotheses with respect to donor-acceptor cyclopropanes. ${ }^{46}$ The authors performed a series of DFT calculations on the reaction between 1,3,5-trimethoxybenzene and cyclopropanes with one or two pendant ester moieties under identical reaction conditions. The protonation of cyclopropane $\mathbf{1 4 2}$ was investigated with and without an explicit solvation effect from three HFIP molecules, which showed that the presence of HFIP facilitates the protonation and, thus, enhances the reactivity of the cyclopropane ring (Scheme 24). The calculations also emphasized that, only when the resulting triflate ion was stabilized by HFIP, the ring-opening could happen before the nucleophilic attack. While the effect of HFIP was not found to significantly alter the mechanism, it lowered the activation barrier of the rate determining step from 29.5 to $20.5 \mathrm{kcal} / \mathrm{mol}$, facilitating the reaction at lower temperatures in agreement with experimental results.
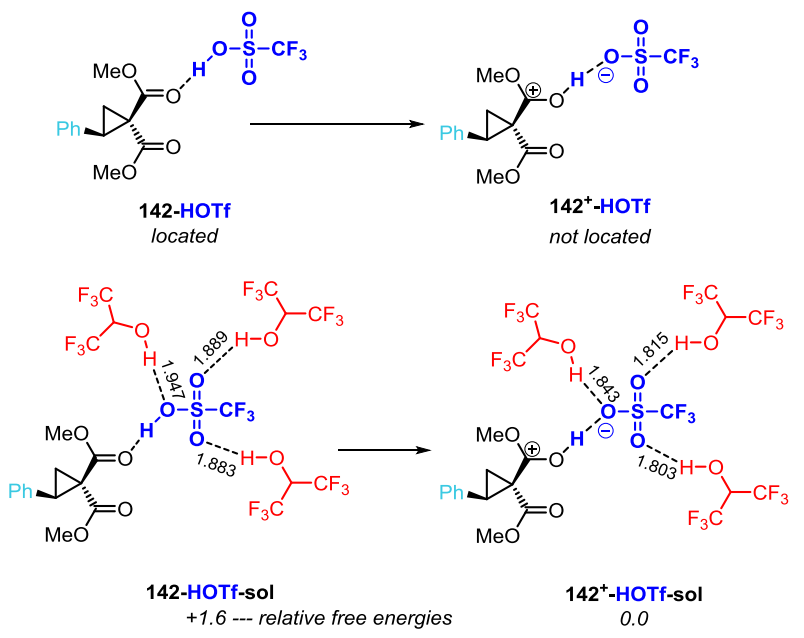

Scheme 24. Possible reactant models without (above) and with (below) incorporation of HFIP solvent molecules. Free energies and $\mathrm{H}$-bond lengths are reported in $\mathrm{kcal} / \mathrm{mol}$ and $\AA$, respectively. 


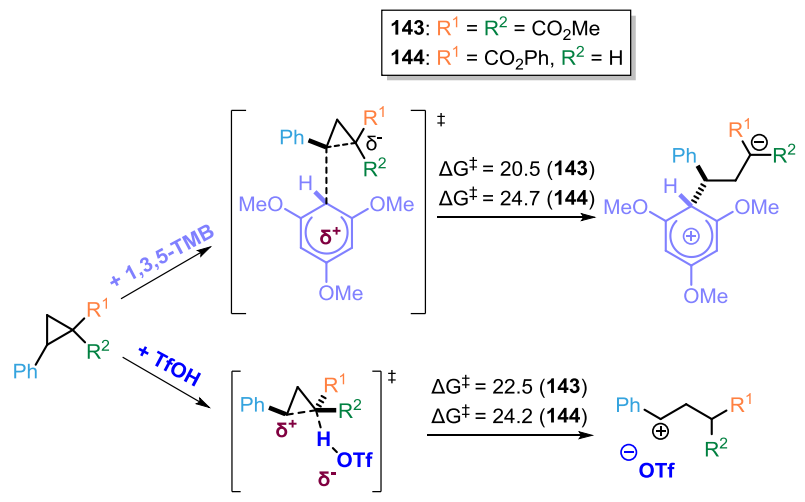

Scheme 25. General modes for ring-opening reaction: nucleophileinduced mechanism (above) and protonation-induced mechanism (below). The activation free energies were reported in $\mathrm{kcal} / \mathrm{mol}$.

Lastly, the reaction was examined with two different cyclopropanes, containing either one or two pendant esters. The nucleophile and proton induced-ring opening were both studied, and it was found that, depending on the case, the reaction likely proceeded through a different pathway (Scheme 25). This was confirmed experimentally as $\mathbf{1 4 4}$ displayed a nucleophile-independent reaction rate, resulting from the fact that the protonation is the rate determining step. These studies taken altogether indicate the critical role played by HFIP in cyclopropane ring-openings.

In contrast, the reactivity of cyclopropyl benzenes with various arene nucleophiles (Scheme 26) proceeds through a different mechanism. ${ }^{44 \mathrm{~b}}$ They reacted even at room temperature to furnish the corresponding products in good to excellent yields. The reaction was not limited to strong nucleophiles and could also be applied to substrates incorporating strong electron-withdrawing groups, such as nitro groups. Control experiments in the absence of nucleophile show that these compounds undergo ring-opening protonation by $\mathrm{TfOH}$ to give a carbocation, leading to a complex mixture of decomposition products. In the presence of the nucleophile, the cation is otherwise trapped to give the observed product, in what could be described as an $\mathrm{S}_{\mathrm{N}} 1$-type mechanism.

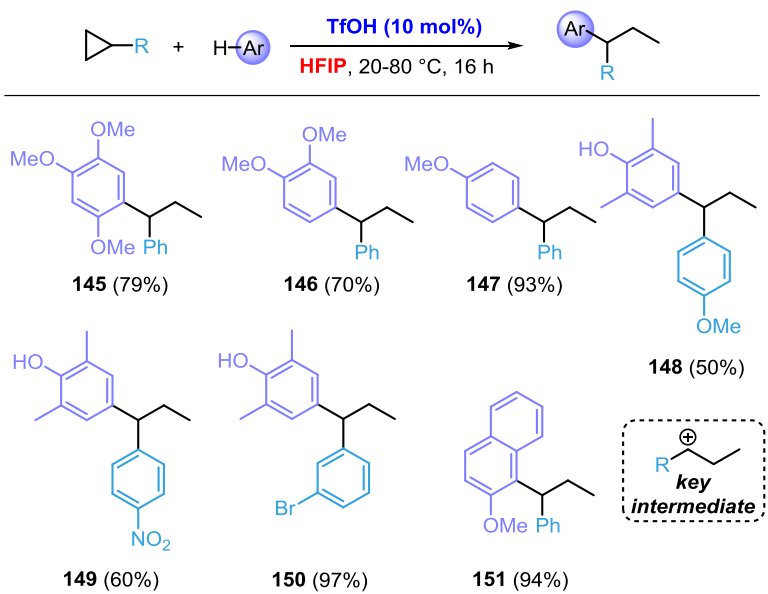

Scheme 26. Triflic acid-catalyzed hydroarylation of cyclopropyl benzenes in HFIP.

\section{Hydrofunctionalizations}

As previously seen for the aza-Piancatelli reaction, the Brønsted acidity of HFIP can be significantly increased by coordination to calcium salts and used to activate alcohols through the formation of a network of hydrogen bonds. In addition, HFIP hydrogen bond networks aid catalytic turnover by facilitating the release of Lewis acids from off-cycle binding with the substrate or product. Therefore, we wondered whether these properties could be exploited for the intra- and intermolecular hydroamidation of unactivated alkenes, ${ }^{47}$ while opening a pathway for substrates considered to be poorly reactive.

Hydroamidation of olefins is commonly used for the synthesis of valuable pyrrolidine and piperidine scaffolds, but prior to our report, the scope of the reaction was subject to several limitations. The most notable were the low tolerance towards substituted alkenes, the need for expensive metal catalysts, poor diastereoselectivity, and the restriction to a limited number of $\mathrm{N}$-protecting groups. The last constraint might be explained by the high Lewis basicity of specific nitrogen functionalities, such as carbamates, amides and ureas, which entrap the catalyst and derail the reaction. However, our optimized protocol featuring $\mathrm{Ca}(\mathrm{II}) / \mathrm{HFIP}$ proved to be compatible with many common $\mathrm{N}$-protecting groups (Fmoc, Bz, carbamoyl, etc.) and alkene substituents, affording pyrrolidine derivatives in high yields (Scheme 27). ${ }^{48}$ Not surprisingly, in the case of intra- or intermolecular hydroamidation of styrenes, the presence of electron-rich functional groups on the aryl moiety had a detrimental effect on the reactivity because of oligomerization side reactions. However, decreasing the amount of HFIP by using a toluene/HFIP 3:1 solvent mixture helped overcome this issue. More importantly, thanks to the high acidity of the promoter system, underexplored highly deactivated styrenes could react in intra- or intermolecular fashion to afford the target products.

To account for the reactivity and the role played by HFIP, we carried out DFT modelling that suggested the formation of a supramolecular entity (Scheme 28). Non-covalent interactions between the $\mathrm{NTf}_{2}$ moiety and the $\mathrm{N}-\mathrm{H}$ functionality, as well as coordination of HFIP to

$$
\text { trans:cis 83:17) }
$$

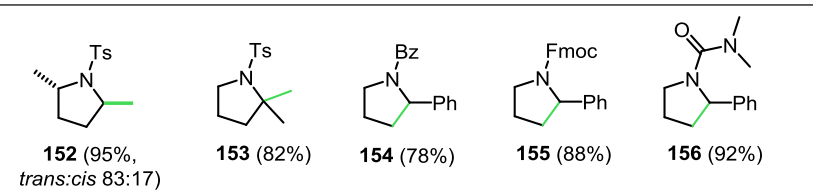

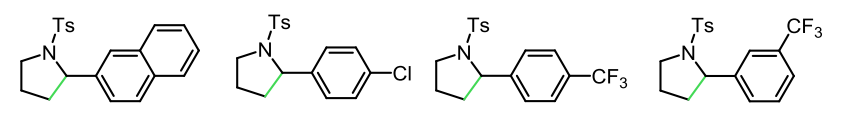

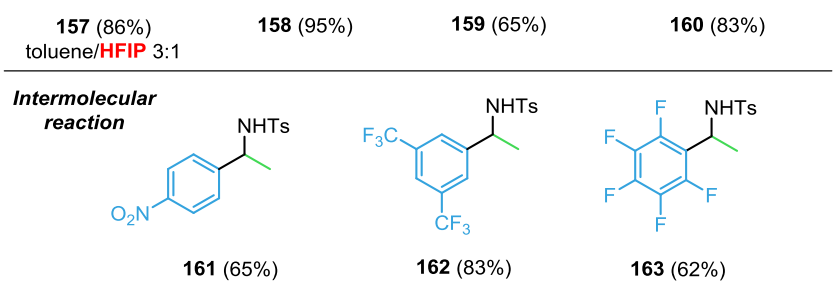

Scheme 27. Calcium(II)-catalyzed hydroamidation of unactivated alkenes and highly deactivated styrenes in HFIP. 


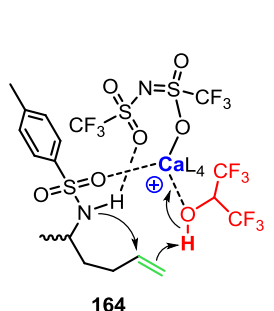

164

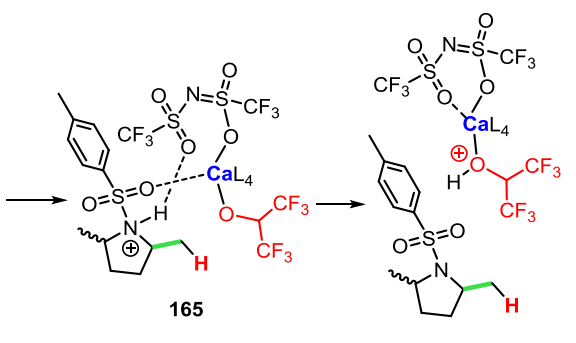

166
Scheme 28. Mechanistic proposal for the hydroamidation of olefins.

the metal, rigidify the substrate conformation to control the diastereoselectivity. HFIP exhibits a dual role: a structural one, in which it assists the assembly of a supramolecular complex, and a catalytic one, in which it aids the protonation of the olefin to trigger the cyclization. Here, the metal serves to augment the acidity of HFIP, which is crucial for activating styrenes that are usually non-reactive for hydroamidation. In other words, the mode of action of the calcium(II)/HFIP system fundamentally differs from a traditional hydroamidation catalyzed by a Lewis or Brønsted acid.

The reactivity of unactivated alkenes was further expanded to unsaturated carboxylic acids to afford $\gamma$-lactones. While those compounds possess a wide range of applications, including drugs, fragrances and food additives, there were only few methods for the hydroacyloxylation of unactivated alkenes. ${ }^{49}$ One issue might be that carboxylic acids are excellent ligands for Lewis acids and transition metals, which could preclude the transformation through coordination to the catalyst. This reaction thus caught our attention and we thought that the properties of our promoter system could tackle this challenge. In that case, the combination of calcium(II)/HFIP proved to be

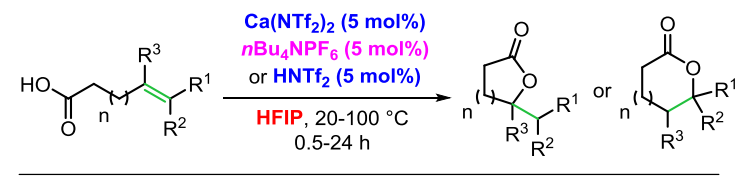

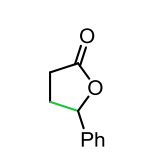

$167(98 \%)$

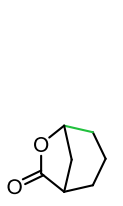

$171(66 \%)$

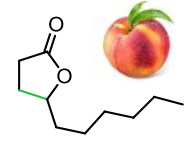

$168(98 \%)$ $\gamma$-decalactone

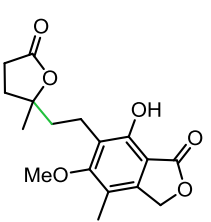

$172(74 \%)$

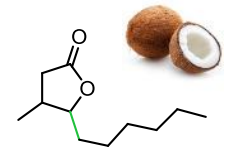

174 (56\%, cis/trans 1:1) cognac lactone

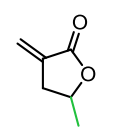

$169(82 \%)$

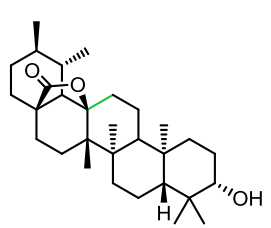

$173(75 \%)$
Scheme 29. Calcium(II)-catalyzed hydroacyloxylation of unactivated alkenes in HFIP. particularly effective to yield the desired compounds from unsaturated carboxylic acids (Scheme 29). ${ }^{50}$ This method could be applied to the synthesis of natural products and to the postfunctionalization of natural and bioactive compounds. However, in the presence of an electron-withdrawing group (EWG) in the $\alpha$ position of the carboxylic acid, the reaction had to be performed with $\mathrm{HNTf}_{2}$ as a catalyst. We presumed that the role of $\mathrm{HNTf}_{2}$ is to disrupt intramolecular $\mathrm{H}$-bonding between the EWG and the carboxylic acid, which otherwise precludes the cyclization. As an example, this reaction yielded $\alpha$-phosphonate $\gamma$-lactones, which constitute excellent synthons to provide $\alpha$-alkylidene $\gamma$-butyrolactones though Horner-Wadsworth-Emmons transformations. ${ }^{51}$

The potential of HFIP in Lewis acid-catalyzed reactions was further illustrated in the synthesis of cis-2,5-disubstituted pyrrolidines with a $\mathrm{N}, \mathrm{O}$-acetal motif (Scheme 30$) .52$ The protocol that features silver(I) acetate as a catalyst delivered the targeted products in high yields and offered excellent control of the diastereoselectivity (>20:1 in most cases). In addition, the authors achieved complete transfer of chirality from an enantiopure precursor. HFIP was found to be essential as it played multiple roles as solvent, proton donor, nucleophile and leaving group.

DFT studies with two explicit HFIP molecules combined with control experiments were carried out to gain insight into the mechanism (Scheme 31). The first step of the proposed mechanism involves the classical formation of a $\pi$-Lewis acid complex $\mathbf{1 8 2}$ followed by a concerted hydroamidation of the alkyne to form the 5-membered nitrogen heterocycle 183. Then, the H-bonded HFIP bridge assists the deprotonation of the quaternary ammonium. The free energy of activation of the overall cyclization was calculated to be 25.8 $\mathrm{kcal} / \mathrm{mol}$, which corresponded to the rate-determining step. Lastly, HFIP induced the proto-demetallation to generate 185 . In the second part of the mechanism, the coordination between silver(I) and HFIP drastically increases the acidity of HFIP to favor the protonation of the enamide, the energy barrier being decreased to $21.9 \mathrm{kcal} / \mathrm{mol}$ in comparison with $i \mathrm{PrOH}(32.9 \mathrm{kcal} / \mathrm{mol})$. While this protonation can still occur in bulk HFIP, it takes place at a slower rate $(48 \mathrm{~h})$ when compared to the reaction in the presence $\operatorname{AgOAc}(3.5 \mathrm{~h})$, in agreement with the harnessing of the acidity of HFIP by silver(I) salts. Once protonated, the heterocycle can undergo nucleophilic addition of HFIP from the same side where the protonation took place.

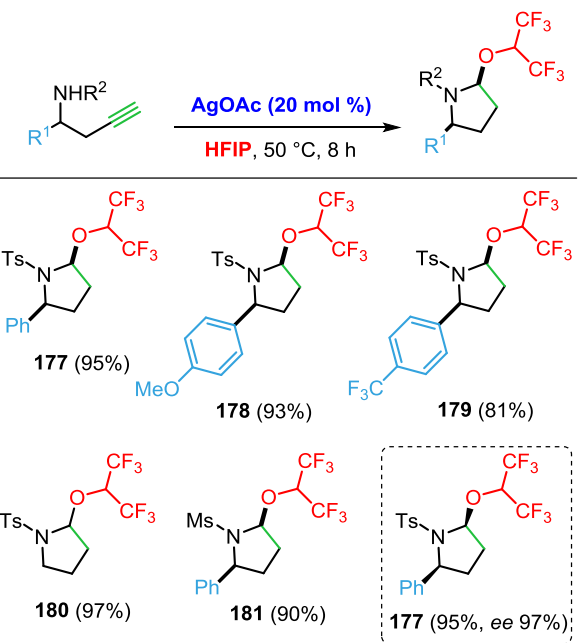

Scheme 30. Silver(I)-catalyzed preparation of pyrrolidines in HFIP. 

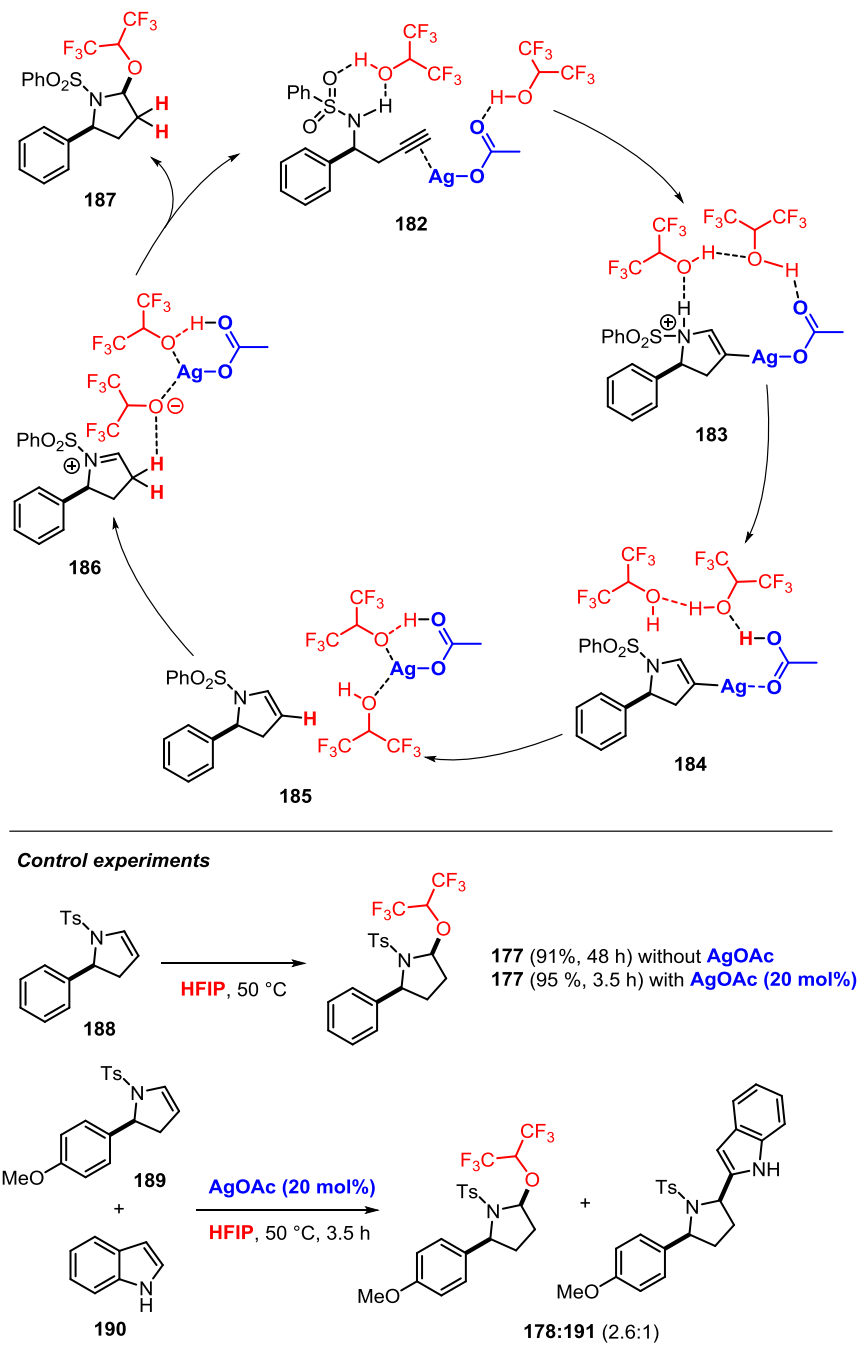

Scheme 31. Mechanistic proposal for the formation of pyrrolidine derivatives in HFIP.

Calculations reveal that the activation free energy for the cis protonation is $1.6 \mathrm{kcal} / \mathrm{mol}$ lower than for the trans approach. A competing experiment with the strong nucleophile indole was also conducted to gauge the nucleophilicity of HFIP. Surprisingly, the $\mathrm{N}, \mathrm{O}$-acetal was obtained as major product, indicating that the nucleophilic addition of HFIP is likely to take place through a metal-HFIP network as suggested by computations. The immediate spatial proximity of HFIP to the electrophilic carbon upon protonation might also have a significant impact on the observed reactivity.

\section{Other Reactions}

A study carried out by the group of Aubé on how to overcome catalyst inhibition during the intramolecular Schmidt reaction revealed another favourable facet of HFIP (Scheme 32). ${ }^{53}$ When the reaction was conducted in dichloromethane (DCM) to provide lactam 192, they noticed that the reaction could be inhibited due to the trapping of the catalyst by the product. However, the reactivity could be restored by performing the reaction in HFIP. In that case, the strong hydrogen bond donor ability displayed by HFIP allows the release of the catalyst and, thus, the turn-over of the process.

However, they did not discard the possibility of forming solvent-acid

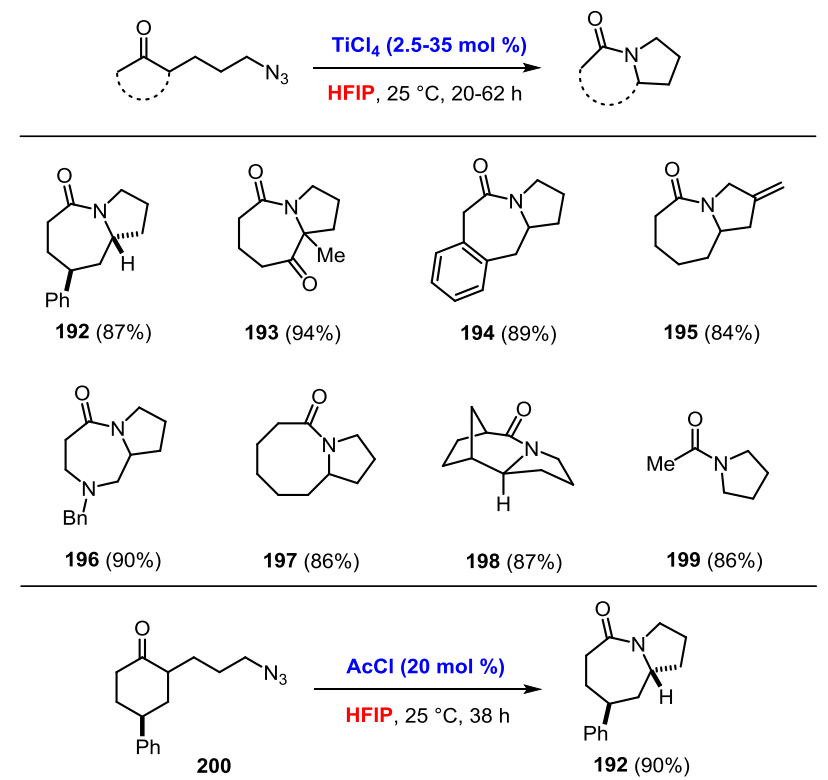

Scheme 32. Titanium(IV)-catalyzed intramolecular Schmidt rearrangement in HFIP.

aggregates, which would be the true catalytically active species. Surprisingly, optimization studies also revealed that acetyl chloride (AcCl) in HFIP could promote the reaction as efficiently as $\mathrm{TiCl}_{4}$. Despite its low nucleophilicity, NMR studies showed that HFIP could displace chloride from $\mathrm{AcCl}$ to yield HFIP acetate and the corresponding $\mathrm{Br} \varnothing n s t e d$ acid $\mathrm{HCl}$, which would promote the reaction. ${ }^{54}$ Again, the authors did not rule out the possibility that the role of $\mathrm{HCl}$ might be to activate the $\mathrm{H}$-bond network of HFIP to trigger the reaction, as appears to be the case for other reactions catalyzed by $\mathrm{TfOH}$ or calcium(II) salts.

Aubé and co-workers followed up with two different Brønsted acidcatalyzed intermolecular Schmidt reactions, the first of which has a unique mechanistic pathway in HFIP (Scheme 33). 55 Depending on the reaction conditions, the lactam is typically formed as the major product in traditional solvents. On the other hand, using TfOH in HFIP provided tetrazole 195 as the major product and the aminotetrazole 196 as minor product under mild conditions. Moreover, 195 could be formed as the sole product by decreasing the amount of TfOH to 5 mol\%. The formation of the tetrazole product had previously been reported from ketones and $\mathrm{TMSN}_{3}$, however, it required high

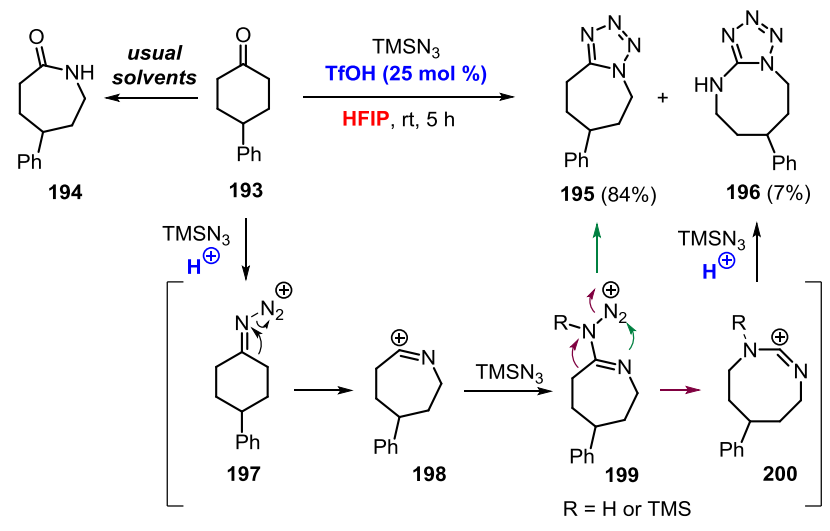

Scheme 33. Access to tetrazoles through intermolecular Schmidt rearrangement in HFIP. 

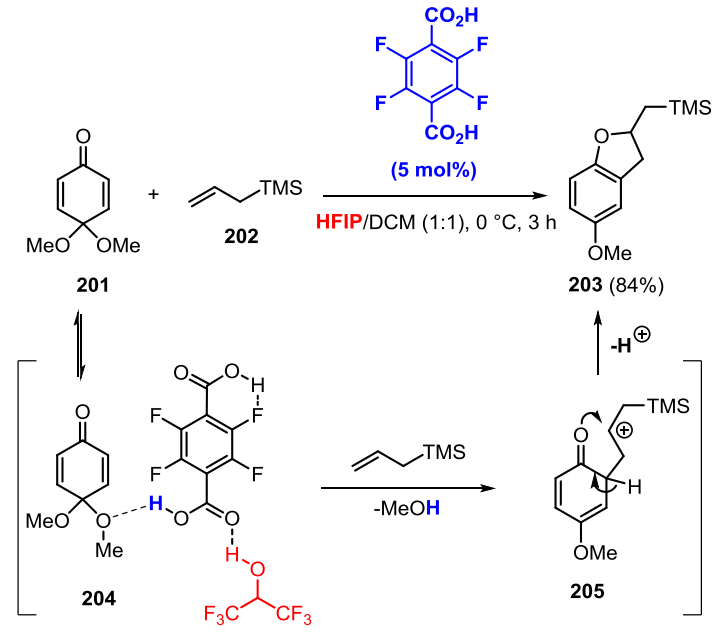

catalytic active species

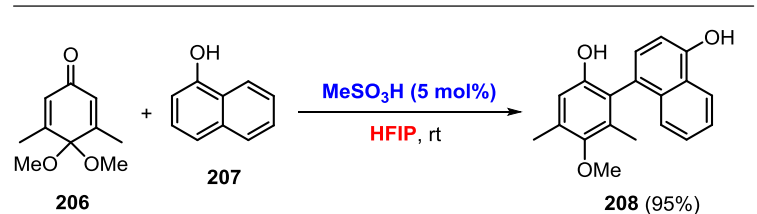

Scheme 34. Tetrafluoroterephtalic acid-catalyzed synthesis of dihydrobenzofurans in HFIP.

temperatures and involved a potentially explosive diazide intermediate. Similarly, an aminotetrazole product had not been previously reported for this reaction. This unique reactivity in HFIP was attributed to its plausible stabilization of the cationic nitrilium intermediate 198, which would allow the nucleophilic addition of a second molecule of $\mathrm{TMSN}_{3}$.

Among other applications of HFIP, the group of Kita reported a Brønsted acid-catalyzed coupling reaction of quinone monoacetals (QMA) with alkenes enabled by HFIP as solvent. ${ }^{56}$ Quinones are attractive building blocks in organic synthesis due to their diverse reactivity and their desymmetrized monoacetal derivatives (i.e. monoprotected quinones) offer increased selectivity in associated transformations. ${ }^{57}$ The method described by Kita and co-workers initially involved the use of a stoichiometric amount of pentafluorobenzoic acid in an HFIP/DCM solvent mixture to trigger the reaction and to deliver dihydrobenzofuran 203.56a The role of HFIP was assumed to harness the acidity of pentafluorobenzoic acid by hydrogen bonding towards the activation of the acetal, in which the conformation of the intermediate blocks the hydrolysis to quinone. This method was further improved by using catalytic amounts of the more acidic tetrafluoroterephtalic acid and stoichiometric amounts of alkene (Scheme 34). ${ }^{56 \mathrm{~b}}$ It was later expanded to the coupling of phenols to produce phenol biaryls, this time using methanesulfonic acid as a catalyst. ${ }^{56 c}$

In liquid and solid states, HFIP forms infinite $\mathrm{H}$-bonded helices containing two microphases. ${ }^{2 b}$ The inner polar microphase along the helix axis contains hydrogen bonded hydroxyl groups, while the outer surface consisting of $\mathrm{CF}_{3}$ groups can be viewed as a hydrophobic microphase. This unique property of HFIP was exploited by Jin $Q u$ and co-workers to develop a cationic polyene cyclization through the action of excess $\mathrm{Ph}_{4} \mathrm{PBF}_{4}$ (Scheme 35). ${ }^{58}$ They claimed that the transformation requires a specific conformation of the polyene and, therefore, interactions between a hydrophobic outer

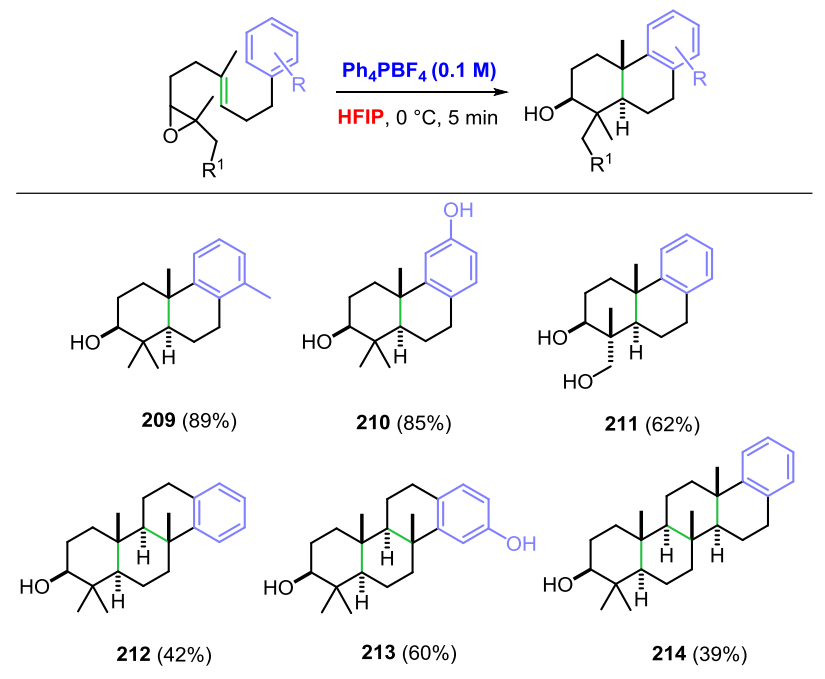

Scheme 35. Tetraphenylphosphonium-promoted polyene cyclization via epoxide ring-opening.

surface of HFIP helices and a hydrocarbon skeleton of a substrate would pre-arrange the latter into a more compacted conformation that would be ideally suited for subsequent polycyclizations. High yields for di-, tri- and even tetracyclizations were reported. Moreover, HFIP is known to produce traces of $\mathrm{HF}$ via solvolysis of $\mathrm{BF}_{4}$ , which would initiate the cascade of reactions by activating the epoxide. However, as the reaction can be performed in the sole presence of HFIP, albeit in a lower yield, the epoxide activation by the $\mathrm{H}$-bonded cluster cannot be ruled out. ${ }^{59}$

\section{Conclusions and Outlook}

Hexafluoroisopropanol possesses great synthetic potential and enables numerous challenging reactions that can deliver complex scaffolds. In addition to its well-known macroscopic properties, recent studies have partially unveiled the role that HFIP might play in reactions involving Lewis and Brønsted acids using DFT computations and NMR studies. However, in-depth investigations regarding the interactions between HFIP and the substrates during the reaction are still highly sought-after. Unfortunately, most studies fail to probe this mechanistic aspect. What seems established is that $\mathrm{H}$-bonded solvent clusters likely act as key players in Lewis and Brønsted acidcatalyzed reactions. Experimental data and DFT calculations suggest the acidity of these aggregates is greatly enhanced upon coordination to the catalyst, which leads to a Lewis or Brønsted acidassisted-Brønsted acid catalysis. In many other cases, the solvent resembles a 'Swiss army knife', as it may assist bond cleavage, stabilize numerous cationic intermediates, prevent catalyst inhibition, pre-organize substrates in favorable conformations and even completely change the reaction pathway. The dynamic permutations of the possible [HFIP-catalyst-substrate] entities exhibit properties of a complex system, where the abovementioned roles may be considered as emergent properties. A better understanding of this system's behavior will pave the way for the rational design of new transformations employing HFIP. Indeed, we still foresee many major improvements through the use of HFIP. Unfortunately, some industrial chemists are hesitant to use it because of its corrosiveness, toxicity (it may cause respiratory irritation when being inhaled and skin burns upon contact), 60 and operational cost $(100 € / \mathrm{kg})$. Hence, it becomes essential to develop methodologies that would reduce the amount of HFIP employed 
while continuing to take advantage of its inherent properties Nevertheless, the cost can be easily overcome by recovering it via distillation, due to its low boiling point $\left(\mathrm{bp}=58^{\circ} \mathrm{C}\right)$. The development of processes for industrial scale recovery of HFIP by co-distillation with heptanes represents a promising solution for its more extensive use. ${ }^{61}$ Finally, none of the examples presented here are enantioselective, despite some stereospecific examples. This is understandable, given the strong $\mathrm{H}$-bond donating ability of HFIP, which prevents the formation of tight ion-pairs with chiral catalysts. In our opinion, the future of fluorinated solvents in catalysis lies in designer variants that overcome these challenges while retaining the aspects that made them attractive in the first place.

\section{Conflicts of interest}

There are no conflicts to declare.

\section{Acknowledgements}

We gratefully thank the French National Research Agency (ANR) through the Programme d'Investissement d'Avenir (ANR-17-EURE0016 funding for V.P. and M.P.), the CNRS and the University of Strasbourg for the support of this work. J.M. was supported by the Agence National de la Recherche through the LabEx "Chemistry of Complex Systems" (ANR-10-LABX-0026 CSC).

\section{Notes and references}

1 For reviews on HFIP, see: (a) J.-P. Bégué, D. Bonnet-Delpon and B. Crousse, Synlett, 2004, 18-29; (b) I. A. Shuklov, N. V. Dubrovina and A. Börner, Synthesis, 2007, 2925-2943; (c) T. Dohi, N. Yamaoka and Y.Kita, Tetrahedron, 2010, 66, 57755785; (d) T. Sugiishi, M. Matsugi, H. Hamamoto and H. Amii, RSC Adv., 2015, 5, 17269-17282; (e) J. Wencel-Delord and F. Colobert, Org. Chem. Front., 2016, 3, 394-400; (f) I. Colomer, A. E. R. Chamberlain, M. B. Haughey and T. J. Donohoe, Nat Rev. Chem., 2017, 1, 0088; (g) S. K. Sinha, T. Bhattacharya and D. Maiti, React. Chem. Engl., 2019, 4, 244-253; (h) X.-D. An and J. Xiao, Chem. Rec., 2020, 20, 142-161; (i) C. Yu, J; SanjoséOrduna, F. W. Patureau and M. H. Pérez-Temprano, Chem. Soc. Rev., 2020, 49, 1643-1652.

2 (a) A. Berkessel and J. A. Adrio, Adv. Synth. Catal., 2004, 346 275-280; (b) A. Berkessel, J. A. Adrio, D. Hüttenhain and J.-M. Neudörfl, J. Am. Chem. Soc., 2006, 128, 8421-8426; (c) A Berkessel and J. A. Adrio, J. Am. Chem. Soc., 2006, 128, 1341213420; (d) A. Berkessel, J. Krämer, F. Mummy, J.-M. Neudörf and R. Haag, Angew. Chem. Int. Ed., 2013, 52, 739-743; (e) O. Hollóczki, A. Berkessel, J. Mars, M. Mezger, A. Wiebe, S. R. Waldvogel and B. Kirchner, ACS Catal., 2017, 7, 1846-1852. For related studies, see also: (f) D. Vuluga, J. Legros, B. Crousse, A. M. Z. Slawin, C. Laurence, P. Nicolet and D. Bonnet-Delpon, J. Org. Chem., 2011, 76, 1126-1133.

3 F. L. Schadt, T. W. Bentley and P. v. R. Schleyer, J. Am. Chem. Soc., 1976, 98, 7667-7674.

4 (a) S. Minegishi, S. Kobayashi and H. Mayr, J. Am. Chem. Soc., 2004, 126, 5174-5181; (b) J. Ammer and H. Mayr, J. Phys. Org. Chem., 2013, 26, 59-63.

5 M. J. Kamlet, J.-L. M. Abboud, M. H. Abraham and R. W. Taft, J. Org. Chem., 1983, 48, 2877-2887.

6 (a) W. J. Middleton and R. V. Lindsey, J. Am. Chem. Soc., 1964, 86, 4948-4952; (b) N. C. Maiti, P. R. Carey and V. E. Anderson, J. Phys. Chem. A, 2003, 107, 9910-9917; (c) J.-F. Berrien, M. Ourévitch, G. Morgant, N. E. Ghermani, B. Crousse and D. Bonnet-Delpon, J. Fluorine Chem., 2007, 128, 839-843; (d) M.
R. Milovanović, Q. Dherbassy, J. Wencel-Delord, F. Colobert, S. D. Zarić and J.-P. Djukic, ChemPhysChem, 2020, doi: 10.1002/cphc.202000560.

7 G. Hallett-Tapley, F. L. Cozens and N. P. Schepp, J. Phys. Org. Chem., 2009, 22, 343-348.

8 C. Reichardt, Chem. Rev., 1994, 94, 2319-2358.

9 (a) M. Rueping and B. J. Nachtsheim, Beilstein J. Org. Chem. 2010, 6, No. 6; (b) R. R. Naredla and D. A. Klumpp, Chem. Rev., 2013, 113, 6905-6948; (c) M. M. Heravi, V. Zadsirjan, P. Saedi and T. Momeni, RSC Adv. 2018, 8, 40061-40163.

10 (a) G. Schäfer and J. W. Bode, Angew. Chem. Int. Ed., 2011, 50, 10913-10916; (b) J. Zhu, M. Pérez and D. W. Stephan, Angew. Chem. Int. Ed., 2016, 55, 8448-8451; (c) G. Pallikonda and M. Chakravarty, J. Org. Chem., 2016, 81, 2135-2142.

11 V. D. Vuković, E. Richmond, E. Wolf and J. Moran, Angew. Chem. Int. Ed., 2017, 56, 3085-3089.

12 For other relevant example using HFIP as a solvent, see: (a) $Q$. Qin, Y. Xie and P. E. Floreancig, Chem. Sci., 2018, 9, 8528-8534; (b) L. Bering, K. Jeyakumar and A. P. Antonchick, Org. Lett., 2018, 20, 3911-3914.

13 X. Creary, Chem. Rev., 1991, 91, 1625-1678.

14 F. Noël, V. Vuković, J. Yi, E. Richmond, P. Kravljanac and J. Moran, J. Org. Chem., 2019, 84, 15926-15947.

15 (a) T. C. Wabnitz, J.-Q. Yu and J. B. Spencer, Chem. Eur. J., 2004, 10, 484-493; (b) T. T. Dang, F. Boeck and L. Hintermann, J. Org. Chem., 2011, 76, 9353-9361; (c) D. Munz, M. WebsterGardiner, R. Fu, T. Strassner, W. A. Goddard, III and T. B. Gunnoe, ACS Catal., 2015, 5, 769-775; (c) C. H. Cheon and H. Yamamoto, Chem. Commun., 2011, 47, 3043-3056.

16 For reviews on boronic acid catalysis, see: (a) E. Dimitrijević and M. S. Taylor, ACS Catal., 2013, 3, 945-962; (b) H. C. Zhang and D. G. Hall, Aldrichimica Acta, 2014, 47, 41-51; (c) D. G. Hall, Chem. Soc. Rev., 2019, 48, 3475-3496.

17 X. Mo, J. Yakiwchuk, J. Dansereau, J. A. McCubbin and D. G. Hall, J. Am. Chem. Soc., 2015, 137, 9694-9703.

18 X. B. Mo, T. D. R. Morgan, H. T. Ang and D. G. Hall, J. Am. Chem. Soc., 2018, 140, 5264-5271.

19 H. T. Ang, J. P. G. Rygus and D. G. Hall, Org. Biomol. Chem. 2019, 17, 6007-6014.

20 (a) H. Yamamoto and K. Futatsugi, Angew. Chem. Int. Ed., 2005, 44, 1924-1942; (b) H. Yamamoto, Tetrahedron, 2007, 63, 8377-8412.

21 S. Zhang, D. Lebœuf and J. Moran, Chem. Eur. J., 2020, 26, 9883-9887.

22 G. C. Welch, L. Cabrera, P. A. Chase, E. Hollink, J. D. Masuda, P. R. Wei and D. W. Stephan, Dalton Trans., 2007, 3407-3414.

23 S.-S. Meng, X. Tang, X. Luo, R. Wu, J.-L. Zhao and A. S. C. Chan, ACS Catal., 2019, 9, 8397-8403.

24 P. A. Champagne, Y. Benhassine, J. Desroches and J.-F. Paquin, Angew. Chem. Int. Ed., 2014, 53, 13835-13839.

25 R. Hemelaere, P. A. Champagne, J. Desroches and J.-F. Paquin, J. Fluor. Chem., 2019, 190, 1-6.

26 J. Wang, Y. Ogawa and N. Shibata, iScience, 2019, 17, 132-143. 27 M. Dryzhakov and J. Moran, ACS Catal., 2016, 6, 3670-3673.

28 For recent reviews, see: (a) C. Piutti and F. Quartieri, Molecules, 2013, 18, 12290-12312; (b) C. Verrier, S. MoebsSanchez, Y. Queneau and F. Popowycz, Org. Biomol. Chem., 2018, 16, 676-687; (c) R. F. A. Gomes, J. A. S. Coelho and C. A. M. Afonso, Chem. Eur. J., 2018, 24, 9170-9186.

29 Herein, the role played by the ammonium salt of weakly coordinating anion consists in promoting an anion metathesis to provide the heteroleptic salt $\mathrm{Ca}\left(\mathrm{NTf}_{2}\right)\left(\mathrm{PF}_{6}\right)$, which is more Lewis acidic than the simple $\mathrm{Ca}\left(\mathrm{NTf}_{2}\right)_{2}$, see: (a) S. Haubenreisser and M. Niggemann, Adv. Synth. Catal., 2011, 353, 469-474; (b) J. Davies and D. Leonori, Chem. Commun., 2014, 50, 15171-15174.

30 D. Lebœuf, E. Schulz and V. Gandon, Org. Lett., 2014, 16, 6464-6467. 
31 D. Lebœuf, L. Marin, B. Michelet, A. Perez-Luna, R. Guillot, E. Schulz and V. Gandon, Chem. Eur. J., 2016, 22, 16165-16171.

32 R. F. Childs, D. L. Mulholland and A. Nixon, Can. J. Chem., 1982, 60, 801-808

33 (a) L. Marin, V. Gandon, E. Schulz and D. Lebœuf, Adv. Synth. Catal., 2017, 359, 1157-1163; (b) L. Marin, R. Guillot, V. Gandon, E. Schulz and D. Lebœuf, Org. Chem. Front., 2018, 5, 640-647.

34 B. Baldé, G. Force, L. Marin, R. Guillot, E. Schulz, V. Gandon and D. Lebœuf, Org. Lett., 2018, 20, 7405-7409.

35 S. Wang, R. Guillot, J.-F. Carpentier, Y. Sarazin, C. Bour, V. Gandon and D. Lebœuf, Angew. Chem. Int. Ed., 2020, 59, 1134-1138.

36 Y. Zhu, I. Colomer, A. L. Thompson and T. J. Donohoe, J. Am. Chem. Soc., 2019, 141, 6489-6493.

37 For reviews on hydroarylation of unactivated alkenes, see: (a) J. R. Andreatta, B. A. Mckeown and T. B. Gunnoe, J. Organomet. Chem., 2011, 696, 305-315; (b) Z. Dong, Z. Ren, S. J. Thompson, Y. Xu and G. Dong, Chem. Rev., 2017, 117, 93339403; (c) Catalytic Hydroarylation of Carbon-Carbon Multiple Bonds; L. Ackermann, T. B. Gunnoe, L. Goj Habgood, L., Eds. Wiley-VCH, 2018.

38 C. Qi, V. Gandon and D. Lebœuf, Angew. Chem. Int. Ed., 2018, 57, 14245-14249.

39 For recent examples of use of HFIP in hydroarylation processes, see: (a) C. D.-T. Nielsen, A. J. P. White, D. Sale, J. Bures, A. C. Spivey, J. Org. Chem., 2019, 84, 14965-14973; (b) I. Colomer, ACS Catal., 2020, 10, 6023-6029.

40 A. Chatupheeraphat, M. Rueping and M. Magre, Org. Lett. 2019, 21, 9153-9157.

41 (a) S. Boldt, S. Parpart, A. Villinger, P. Ehlers and P. Langer, Angew. Chem. Int. Ed., 2017, 56, 4575-4578; (b) W. Yang, R. Bam, V. J. Catalano and W. A. Chalifoux, Angew. Chem. Int Ed., 2018, 130, 14989-14993.

42 I. Takahashi, T. Fujita, N. Shoji and J. Ichikawa, Chem. Commun., 2019, 55, 9267-9270.

43 (a) H.-U. Reissig and R. Zimmer, Chem. Rev., 2003, 103, 1151 1196; (b) T. F. Schneider, J. Kaschel and D. B. Werz, Angew. Chem. Int. Ed., 2014, 53, 5504-5523.

44 (a) E. Richmond, V. Vuković and J. Moran, Org. Lett., 2018, 20 574-577; (b) E. Richmond, J. Yi, V. D. Vuković, F. Sajadi, C. N. Rowley, J. Moran, Chem. Sci., 2018, 9, 6411-6416.

45 For other relevant examples of reactions involving donoracceptor cyclopropanes in HFIP, see: (a) Y.-C. Luo, H. Ma, X.Q. Hu and P.-F. Xu, J. Org. Chem., 2017, 82, 1013-1023; (b) H. Ma, X.-Q. Hu, Y.-C. Luo and P.-F. Xu, Org. Lett., 2017, 19, 66666669; (c) M. A. Boichenko, I. A. Andreev, A. O. Chagarovskiy, I. I. Levina, S. S. Zhokhov, I. V. Trushkov and O. A. Ivanova, J. Org. Chem., 2020, 85, 1146-1157.

46 Y. Zhou, R. Xue, Y. Feng and L. Zhang, Asian J. Org. Chem., 2020, 9, 311-316.

47 (a) T. E. Müller, K. C. Hultzsch, M. Yus, F. Foubelo and M. Tada, Chem. Rev., 2008, 108, 3795-3892; (b) L. Huang, M. Arndt, K. Gooßen, H. Heydt and L. J. Gooßen, Chem. Rev., 2015, 115 2596-2697; (c) E. Bernoud, C. Lepori, M. Mellah, E. Schulz and J. Hannedouche, Catal. Sci. Technol., 2015, 5, 2017-2037; (d) A. L. Reznichenko and K. C. Hultzsch. In Organic Reactions; S E. Denmark, Ed.; Wiley \& Sons: New York, 2015; Vol. 88.

48 C. Qi, F. Hasenmaile, V. Gandon and D. Lebœuf, ACS Catal., 2018, 8, 1734-1739.

49 R. R. A. Kitson, A. Millemaggi and R. J. K. Taylor, Angew. Chem. Int. Ed., 2009, 48, 9426-9451; (b) B. Mao, M. Fañanas-Mastral and B. L. Feringa, Chem. Rev., 2017, 117, 10502-10566.

50 C. Qi, S. Yang, V. Gandon and D. Lebœuf, Org. Lett., 2019, 21 7405-7409.

51 M. G. Lloyd, R. J. K. Taylor and W. P. A. Unsworth, Org. Lett., 2014, 16, 2772-2775.
52 W. Wang, X. Cao, W. Xiao, X. Shi, X. Zuo, L. Liu, W. Chang and J. Li, J. Org. Chem., 2020, 85, 7045-7059.

53 H. F. Motiwala, C. Fehl, S. W. Li, E. Hirt, P. Porubsky and J. Aubé, J. Am. Chem. Soc., 2013, 135, 9000-9009.

54 For related studies with HFIP by the same group, see: (a) H. F. Motiwala, R. H. Vekariya and J. Aubé, Org. Lett., 2015, 17, 5484-5487; (b) S. Roy, H. F. Motiwala, K. M. Koshlap and J. Aubé, Eur. J. Org. Chem., 2018, 306-315.

55 H. F. Motiwala, M. Charaschanya, V. W. Day, and J. Aubé, J. Org. Chem., 2016, 81, 1593-1609.

56 (a) T. Dohi, Y. Hu, T. Kamitanaka, N. Washimi and Y. Kita, Org Lett., 2011, 13, 4814-4817; (b) Y. Hu, T. Kamitanaka, Y. Mishima, T. Dohi and Y. Kita, J. Org. Chem., 2013, 78, 55305543; (c) T. Kamitanaka, K. Morimoto, K. Tsuboshima, D. Koseki, H. Takamuro, T. Dohi and Y. Kita, Angew. Chem. Int. Ed., 2016, 55, 15535-15538.

57 D. Magdziak, S. J. Meek and T. R. R. Pettus, Chem. Rev., 2004 104, 1383-1430.

58 Y. Tian, X. Xu, L. Zhang and J. Qu, Org. Lett., 2016, 18, 268-271.

59 For an example of HFIP-promoted epoxide ring-opening in Friedel-Crafts alkylation, see: G.-X. Li and J. Qu, Chem. Commun., 2010, 46, 2653-2655.

60 For more details, see the safety data sheet of HFIP https://www.fishersci.com/shop/msdsproxy?storeld=10652 \&product Name $=$ AC293410500

61 S. J. Brenek, S. Caron, E. Chisowa, M. P. Delude, M. T. Drexler, M. D. Ewing, R. E. Handfield, N. D. Ide, D. V. Nadkarni, J. D. Nelson, M. Oliver, H. H. Perfect, J. E. Phillips, J. J. Teixeira, R. M. Weekly and J. P. Zelina, Org. Process Res. Dev., 2012, 16, 1348-1359. 